\title{
Mechanical properties and debonding strength of Fabric Reinforced Cementitious Matrix (FRCM) systems for masonry strengthening
}

\author{
Francesca Giulia Carozzi *, Carlo Poggi \\ Department ABC - Architecture, Built Environment and Construction Engineering, Politecnico di Milano, Piazza Leonardo da Vinci, 20133 Milano, Italy
}

\section{ABSTRACT}

Fabric Reinforced Cementitious Matrix (FRCM) composites are advanced cement-based materials often used for strengthening masonry or concrete structures. The system is usually composed of a dry grid of fibers embedded in a cementitious matrix enriched with short fibers.

An important parameter for designing the structural reinforcement is the tensile load-bearing capacity of FRCM composites. For their heterogeneity, FRCM composites show an interesting mechanical behavior in tension, that depends on the properties of the components and of the bonding strength. These values could be estimated with mechanical models but must be validated experimentally by means of proper testing campaigns.

In this work several FRCM materials made with different fiber grids were investigated. Four different types of fibers were considered: polyparaphenylene benzobisoxazole (PBO), carbon $(C)$, glass $(G)$ and $\mathrm{PBO}$ and glass (PBO-G) fibers and three different types of cementitious mortars.

The behavior of FRCM under tension and the influence of the bond properties between the dry textile and the inorganic matrix are studied developing an extensive experimental program that included the characterization both of the materials components and of the composites. A series of push-pull double lap tests and pull-off tests were performed to determine the bonding properties of FRCM composites applied to masonry structures.

The paper presents results and considerations that can provide background data for future recommen-dations for the use of FRCM systems in the rehabilitation of elements.

\section{Introduction}

Continuous fiber-reinforced materials with polymeric matrix (FRP) are nowadays widely used for strengthening and retrofitting existing masonry and concrete structures. The use of FRP strips as reinforcements instead of conventional methods is a suitable solution for the seismic upgrading.

These materials present many advantages: lightweight, speed of execution, good mechanical properties and good performance at failure [1-4]. They have also some drawbacks: poor behavior at high temperatures, relatively high cost of epoxy resins, lack of vapor permeability, incompatibility of resins and substrate materials, no reversibility of the installation [5]. The replacement of organic matrix with inorganic ones represents a solution to these drawbacks.

During the last two decades, the use of pre-fabricated cementbonded fibers has increased. Such elements are used for many applications like cladding panels, exterior siding, pressure pipes,

* Tel.: +39 0223994351.

E-mail address: francescagiulia.carozzi@polimi.it (F.G. Carozzi). tiles for roofs and floors. The reinforcement can be either made with short fibers (Fiber reinforced concrete, FRC) or with continuous fibers in a fabric form (Textile Reinforced Concrete, TRC) [6].

Fiber reinforced concrete is made with hydraulic cement, aggregates of various sizes and discontinuous short fibers. Since the early use of asbestos fibers, a wide variety of other fibers have been used with hydraulic cements: conventional fibers as steel and glass, new fibers as carbon or Kevlar and low modulus fibers as polypropylene or natural fibers. In TRC the fibers are usually pre impregnated with resin and this influences their mechanical properties that depend on the bond between the fibers and the matrix.

Fabric Reinforced Cementitious Matrix (FRCM) composites represent a particular type of TRC where dry-fibers in textile form are impregnated with a cementitious mortar enriched with short fibers. The multifilament yarns are usually disposed in grids and made of alkali-resistant AR glass, carbon or polymer fibers. The matrix is typically a grout system based on cement and a low dosage of dry organic polymers (less than $5 \%$ by weight). The organic compounds are necessary to ensure proper workability, setting time and mechanical properties [6]. 


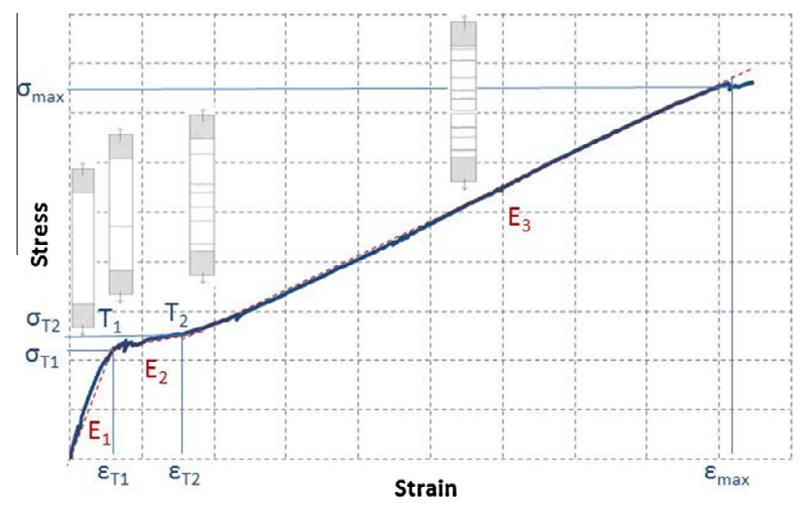

Fig. 1. Stress-strain behavior of FRCM composites subjected to tensile test.

FRCM composites are particularly indicated in the reinforcement of historical buildings, due to the higher compatibility with the substrates, vapor permeability and durability to external agents $[7,8]$ and the major reversibility of the intervention. In fact the organic matrices penetrate into the substrate while the inor-ganic matrices cannot cause any damage. An overview of the use of FRCM can be found in [9-14]. To design the structural reinforce-ment both the values of the mechanical properties of the applied materials and their bonding resistance to the substrate are needed. These values may be determined only by appropriate experiments possibly made in specialized laboratories on an adequate number of specimens made with the same system of reinforcement and manufacturing techniques. The test procedures need to be defined in details and reported in guidelines or recommendations. A relevant work has been done in this direction by a RILEM Technical Committee (232-TDT).

Various set-ups for tensile tests on FRCM specimens have been developed $[15,16]$. The specimen production, dimension and shapes and load application may largely influence the stress-strain behavior of these materials. Hartig et al. [17] classified two types of load application: "rigid load application" in which the main transfer mechanism between the specimen and the clamping is made with an adhesive in tension and shear and "soft clamping" with friction load transfer allowing for gradual load application.

This paper presents experimental results that can provide background data for future recommendations in this field. In this project specimens dimension and type of load application were decided in accordance with both the American code AC 434 [18] and the instruction provided by RILEM technical committee 232TDT.

Another important aspect is the bond strength of the FRCM materials applied on masonry elements and the slippage phenomena at the interface mortar-textile and substrate-composite. The following failure modes could be identified during a push-pull shear test [36]: debonding at the substrate-composite interface, delamination of the composite at the matrix-textile interface and slipping of the fibers into the matrix. Many factors influence the bond strength of the FRCM system: the mechanical properties of textile and matrix, the mortar capability to penetrate into the grid and the friction between the filaments.

Several studies were developed to analyze these aspects for FRPs used in reinforcing concrete and masonry elements. On the contrary only few studies have been dedicated to FRCM systems $[23,36,37]$. In this paper the bonding behavior of the FRCM systems was investigated to analyze both the adherence between the reinforced system and the substrate and between the dry textile and the cementitious mortar. For this purpose, push-pull double lap tests and pull-off tests were carried out on different FRCM materials applied on clay bricks with different mechanical properties.

\section{Mechanical behavior of FRCM in tension}

A typical stress-strain behavior of FRCM under tensile test is represented in Fig. 1. The curve can be considered tri-linear: the first phase represents the uncracked state, where the slope of stress-strain curve reflects the elastic modulus of the matrix. The second phase corresponds to the formation of cracks. In this state
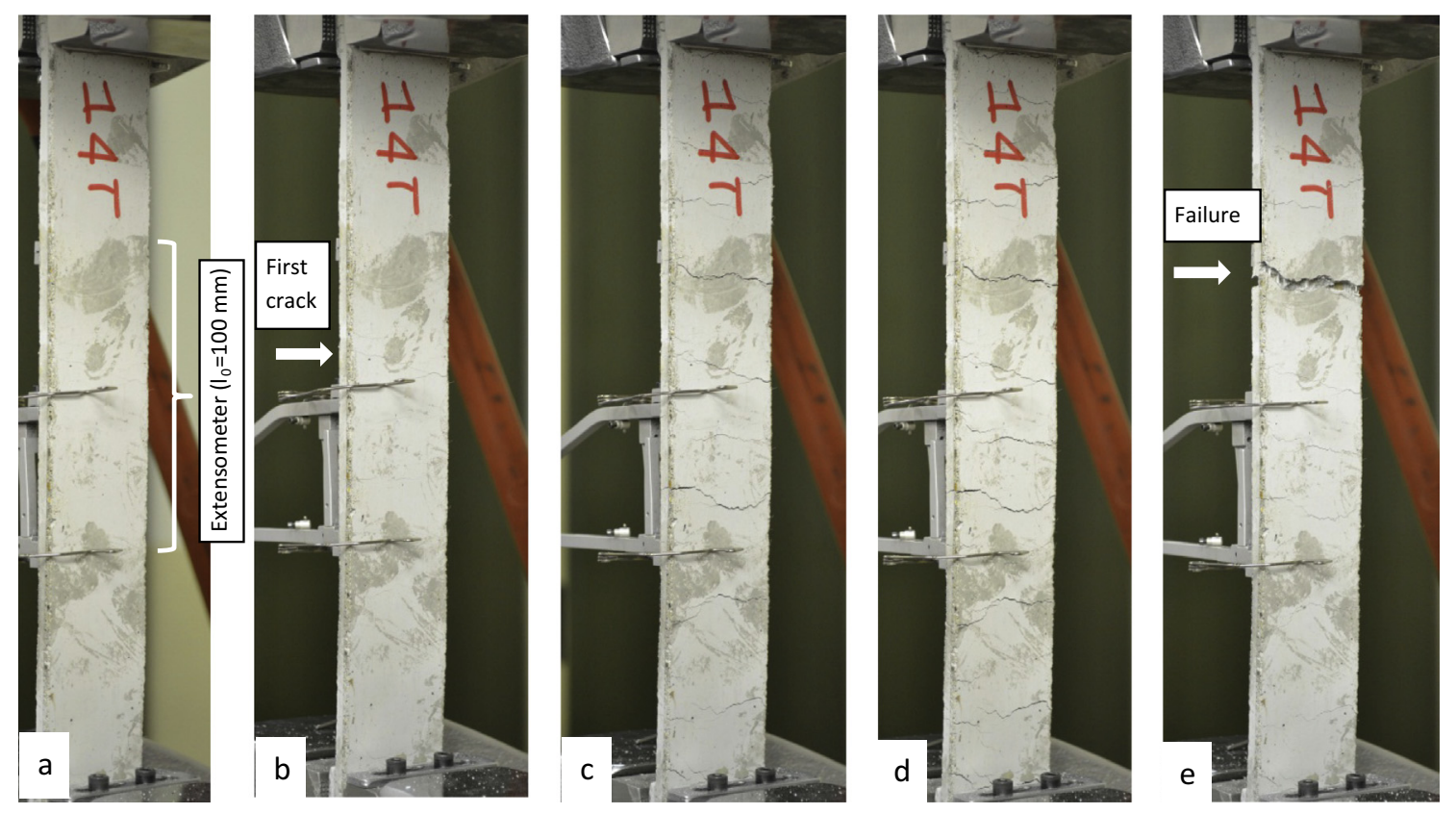

Fig. 2. Failure mode of FRCM composites subject to tensile test: (a) unloaded specimen; (b) first crack (point $T_{1}$ in Fig. 1); (c) multiple cracks in the mortar (point $T_{2}$ in Fig. 1); (d) fully cracked specimen; e) ultimate failure. 
there is a significant decrease of the stiffness and relatively fine cracks grow with the tensile load. The length and slope of this portion of the curve depend on the quality of the bond between textile and matrix and on the volume proportion of the fibers activated for the load transfer [8]. The geometry of the textile, as shown in Chapter 6 , could be correlated with the location and the width of the cracks.

The third phase is the crack-widening region, where the existing cracks become wider up to the final failure that can be compared with the tensile strength of the textile. In few tests where the transition from second to third phase was not evident (point T2), some extra cracks developed also in the third phase. In this phase the only resistant part in the composite is the fabric and, therefore, the slope of the curve should reflect the elastic modulus of the dry fibers. As showed in Fig. 1, the points $T_{1}$ and $T_{2}$ are defined by a slope change of the stress-strain curve and may be determined by the intersection of the lines tangent to each phase.

Fig. 2 shows the different phases of the test, the cracking of the specimens and the failure modes.

The main significant parameters are:

- Tensile stresses and strains in the transition point between two phases (point $\mathrm{T}_{1}$ and $\mathrm{T}_{2}$ ), $\sigma_{\mathrm{T} 1}, \sigma_{\mathrm{T} 2}, \varepsilon_{\mathrm{T} 1}, \varepsilon_{\mathrm{T} 2}$.

- Stiffness of the phases $E_{1}, E_{2}, E_{3}$.

- Ultimate tensile stress and strain, $\sigma_{\mathrm{u}}, \varepsilon_{\mathrm{u}}$.

These stresses are determined dividing the load by the transversal area of the fibers that are known. On the contrary the thickness of the matrix is quite variable and is a priori unknown.

As an alternative the tensile stress in the first phase can be calculated also dividing the load by the mortar area when the aim is to compare the elastic modulus with the one of the mortar and the stress of the uncracked mortar in $\mathrm{T}_{1}$ with the maximum tensile stress of the mortar.

In this work different types of FRCM materials were analyzed. For each typology a mechanical characterization was carried out for the components (cementitious mortar and fiber grid) and the composite.

\section{Materials}

The studied FRCM systems consist of two main elements, a cementitious mortar enriched with a low dosage of dry polymers and a fiber grid. In this study different types of fiber grids were investigated: polyparaphenylene benzobisoxazole ("PBO-1 fiber" and "PBO-2 fiber"), glass ("G fiber"), carbon ("C fiber") and an hybrid grid composed of PBO and glass fibers ("PBO-G fibers"). Each type of fiber was correlated with a specific mortar. The corresponding system are denominated "PBO1-FRCM"; "PBO2-FRCM"; "G-FRCM"; “C-FRCM"; "PBO-G-FRCM".

\subsection{Textile reinforcements}

The "PBO-1" fiber unbalanced net is made of $10 \mathrm{~mm}$ and $20 \mathrm{~mm}$ spaced rovings (Fig. 3a). The free space between rovings is roughly $5 \mathrm{~mm}$ and $15 \mathrm{~mm}$ respectively, and the equivalent thickness in the two fibers directions is $0.046 \mathrm{~mm}$ and $0.011 \mathrm{~mm}$ respectively.

The "PBO-2" fiber balanced net is made of $12 \mathrm{~mm}$ spaced rovings. The free space between rovings is roughly $10 \mathrm{~mm}$, and the equivalent thickness is $0.014 \mathrm{~mm}$ (Fig. 3b).

The glass fiber unbalanced net presents a coating in Styrene Butadiene Rubber (SBR) that provides a resistance to alkaline environments. The free space between yarns is $17 \times 12 \mathrm{~mm}$ (Fig. 3c).
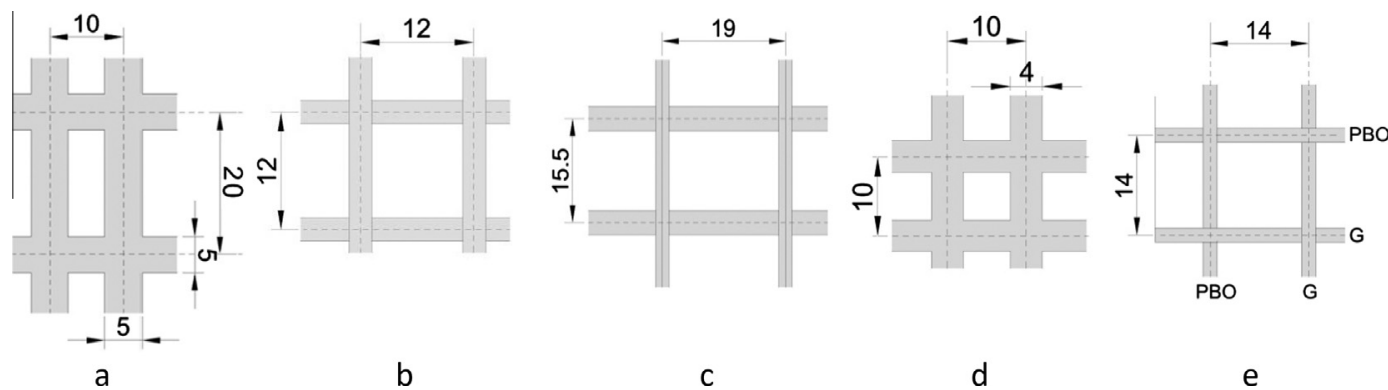

Fig. 3. Geometrical dimensions: (a) PBO-1 fiber mesh; (b) PBO-2 fiber mesh; (c) Glass fiber mesh; (d) Carbon fiber mesh; (e) PBO-G fiber mesh.
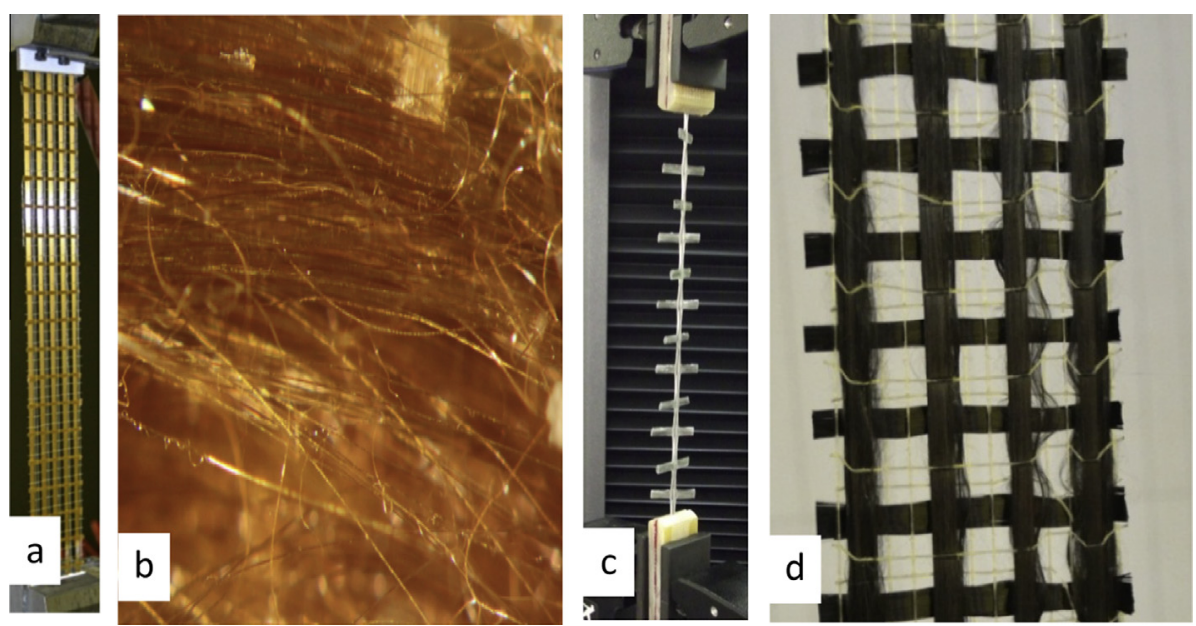

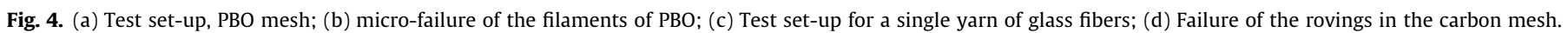


The carbon fiber is a balanced net with fiber rovings disposed in two orthogonal directions at a nominal spacing of $10 \mathrm{~mm}$ (Fig. 3d). The equivalent fiber thickness is $0.047 \mathrm{~mm}$ in both directions.

The "PBO-G" net is composed of PBO and glass fibers rovings. The free space between rovings is $14 \mathrm{~mm}$ and the equivalent thickness is $0.0064 \mathrm{~mm}$ (Fig. 3e).

In all the geometries, excluding the glass textile, the longitudinal and transversal yarns are not glued together, but woven and fixed with small nylon fibers (Fig. 4a and d).

Tensile tests of the dry fibers were performed according to EN ISO $10618 / 2005$ [20] on a single roving in warp and weft directions and on a grid strip of width 4 and $5 \mathrm{~cm}$ in the warp direction. Tests were carried out using different testing machines with maximum load capacities of $2 \mathrm{kN}$ and $100 \mathrm{kN}$ and an extensometer with base length equal to $50 \mathrm{~mm}$. In order to avoid local damage in the specimens during the tensile tests, special tabs of fiberglass were bonded using epoxy resin at the ends of the specimens. The tabs presented a width equal to the sample and a length equal to $60 \mathrm{~mm}$.

The experimental results are summarized in Tables 1 and 2. The failure mode shows a rupture of some filaments without a complete failure of the roving. Fig. 4 shows the test set-up and the failure modes.

Different values of the ultimate strength were determined in the case of PBO-1 fibers. The main reason of the difference between the single roving and the grid is certainly due to an irregular distribution of the stresses in the four yarns. The different tensions in each roving are not easy to determine experimentally as even the tensile test on dry fibers is a difficult task influenced by the number of fibers in each yarn and their distribution. Tabs made with GFRP were used to distribute the stresses in the grids but the irregularities in the load distribution are difficult to avoid. The problem was limited to PBO-1 fibers while the other results could be considered satisfactory.

\subsection{Cementitious matrix}

Three types of mortars were considered. Table 3 shows the main mechanical properties and the corresponding experimental standard $[21,34,35]$. Some of the values were verified by the authors while others were taken from the technical data-sheets provided by the producer. The technical data sheets should give indications about the possible types of fibers that can be coupled with a mortar. The properties of the mortars are usually the result of long and deep research activities to find the best coupling mainly in terms of bonding properties and therefore some of the constitutive components of the mortar may be confidential.

\section{Specimen preparation and test set up for tensile tests}

\subsection{Specimen geometry and preparation}

In order to investigate the mechanical behavior of FRCM systems, tensile tests were carried out on several series of specimens. In the following part the test set-up is described and the main results of the experimental program are reported.

Tensile coupons were made in a flat mold by applying a first layer of cementitious mortar $(5 \mathrm{~mm})$, the fiber mesh and a second layer of cementitious mortar $(5 \mathrm{~mm})$. The curing lasted 28 days. In the curing phase is important to pay attention to the possibility that some micro-cracks develops due to a non-homogeneous shrinkage.

The coupons (Fig. 6) were all rectangular (nominal size $400 \times 40 \times$ $10 \mathrm{~mm}$ ). Table 4 shows the variability of the specimen transversal area due to the non-constant thickness. This is a very important parameter in the following analysis of the first phase

Table 1

Tensile tests on single dry roving.

\begin{tabular}{|c|c|c|c|c|c|c|c|}
\hline Material & Tensile tests & Cross section area $\left(\mathrm{mm}^{2}\right)$ & \# tests & Average failure stress (MPa) & $\operatorname{CoV}(\%)$ & Elastic modulus (GPa) & $\mathrm{CoV}(\%)$ \\
\hline \multirow[t]{2}{*}{ PBO-1 fiber } & Roving in the warp direction & 0.41 & 6 & 3900 & 3.2 & 215.9 & 20.8 \\
\hline & Roving in the weft direction & 0.21 & 2 & 3430 & - & 276.6 & - \\
\hline PBO-2 fiber & Roving & 0.22 & 3 & 3175 & 2.4 & - & - \\
\hline \multirow[t]{2}{*}{ Glass fiber } & Yarn in the warp direction & 0.90 & 5 & 1233 & 2.7 & 55.6 & 30.5 \\
\hline & Yarn in the weft direction & 0.92 & 5 & 1120 & 1.7 & 60.5 & 28.2 \\
\hline Carbon fiber & Roving & 0.42 & 3 & 1944 & 14.9 & 203.0 & 9.8 \\
\hline
\end{tabular}

Table 2

Tensile tests on dry grid strip.

\begin{tabular}{|c|c|c|c|c|}
\hline Material & Tensile tests & \# tests & Average failure stress (MPa) & $\operatorname{CoV}(\%)$ \\
\hline \multirow[t]{2}{*}{ PBO-1 fibers } & Grid strip of width $4 \mathrm{~cm}$ (4 rovings) & 4 & 3397 & 7.3 \\
\hline & Grid strip of width $5 \mathrm{~cm}$ (5 rovings) & 6 & 3395 & 11.7 \\
\hline Glass fibers & Grid strip of width $5 \mathrm{~cm}$ ( 3 yarns in the warp direction) & 5 & 1121 & 1.3 \\
\hline Carbon fibers & Grid strip of width $4 \mathrm{~cm}$ ( 4 rovings in the warp direction) & 3 & 1913 & 10.4 \\
\hline PBO-G fibers & Grid strip of width $4 \mathrm{~cm}$ (2 PBO rovings and 1 Glass roving) & 3 & 2996 & 11.9 \\
\hline
\end{tabular}

Table 3

Mechanical properties of the mortars.

\begin{tabular}{|c|c|c|c|c|c|c|c|}
\hline \multirow[t]{2}{*}{ Material } & \multicolumn{2}{|c|}{$\begin{array}{l}\text { Tensile test (MPa) } \\
\text { EN 12390-6 }\end{array}$} & \multicolumn{2}{|l|}{$\begin{array}{l}\text { Compressive test (MPa) } \\
\text { EN 1015-11 }\end{array}$} & \multicolumn{2}{|l|}{$\begin{array}{l}\text { Flexural strength (MPa) } \\
\text { EN 1015-11 }\end{array}$} & \multirow[t]{2}{*}{$\begin{array}{l}\text { Elastic modulus (GPa) } \\
\text { EN } 14580\end{array}$} \\
\hline & Tensile strength & $\mathrm{CoV}(\%)$ & Compressive strength & $\operatorname{CoV}(\%)$ & Compressive strength & $\operatorname{CoV}(\%)$ & \\
\hline Mortar used with PBO fibers & $4.75(7)$ & 4.05 & >15 (data sheet) & & >2 (data sheet) & & $>6$ (data sheet) \\
\hline Mortar used with glass fibers & - & - & $27.13(7)$ & 4.10 & $8.38(14)$ & 13.15 & 8 (data sheet) \\
\hline Mortar used with carbon fibers & - & - & $>20$ (data sheet) & & 3.5 (data sheet) & & >7 (data sheet) \\
\hline
\end{tabular}

Note: Within brackets \# of tested samples or font of the data. 
Table 4

Average specimens size.

\begin{tabular}{|c|c|c|c|c|c|}
\hline Material & Section $\max \left(\mathrm{mm}^{2}\right)$ & Section $\min \left(\mathrm{mm}^{2}\right)$ & Section average $\left(\mathrm{mm}^{2}\right)$ & $\operatorname{CoV}(\%)$ & Volumetric reinforcement ratio \\
\hline PBO1-FRCM & 478.1 & 263.9 & 382.9 & 16.9 & 0.0041 \\
\hline G-FRCM & 450.5 & 380.2 & 410.6 & 4.1 & 0.0045 \\
\hline C-FRCM & 367.3 & 300.2 & 340.7 & 6.4 & 0.0042 \\
\hline
\end{tabular}

of the tensile tests. Due to the difficulties in defining a specific volumetric reinforcement ratio for each specimen, only one nominal volumetric reinforcement ratio was adopted for each composite material making reference to the nominal mortar area (400 $\mathrm{mm}^{2}$ ). The values of the volumetric reinforcement ratio are showed in Table 4.

Another important aspect for FRCM composites is the behavior of multi layers FRCM composites. These are not examined in this work. Only few specimens were prepared to analyze the specific problem of the overlapping of the textile in a single layer specimen. The technique of overlapping is often adopted in the application of FRCM to strengthen large structural elements. These samples were realized with the same technique and with a similar geometry. Only preliminary test were performed but we can conclude that if the overlapping is located in a central part of the specimen, with a length of at least $100 \mathrm{~mm}$ the failure mode is similar to that of original samples without grid overlapping but in the third phase slippage phenomena were highlighted between the fibers and the matrix. This problem should be studied in future projects.

\subsection{Clamping}

Tensile tests were carried out according to Annex A of AC 434 [17], but with a different gripping mechanism. The US Standards recommend a clamping method with Clevis-type grips and one of the two grips shall allow for rotation in two perpendicular planes to avoid the negative effects of possible eccentricity and misalignments [19]. In this project an alternative system was studied and adopted after a comprehensive comparison of the two methods. In the adopted clamping system the two extremes of the speci-mens were fixed into the grips of a standard testing machine but the lower grip allowed for torsional rotation. In this case the clamps can produce high compressive stresses at the end of the specimens. For this reason fiber reinforced tabs (dimensions $60 \times 40 \times 2 \mathrm{~mm}$ ) were applied using epoxy resins after sand blast-ing of the extremes. After several tests for comparison it was con-cluded that this clamping method was satisfactory and preferable. Furthermore it gives the possibility to reach the ultimate stress of the textile reinforcement and explore the third phase of the stress-strain plot (see Fig. 1) limiting the slipping of the fibers. On the contrary the US standard foresee a bilinear behavior of the com-posite limiting the analysis to the first two phases. An example of the results obtained using the two methods of clamping is reported in Fig. 5. The longer extension of the curve obtained with the present clamping system is evident.

\subsection{Instrumentation}

A testing machine with load capacity of $100 \mathrm{kN}$ was used with displacement control at a rate of $0.1 \mathrm{~mm} / \mathrm{min}$ in the first phase. After the cracking, the speed was increased to $0.5 \mathrm{~mm} / \mathrm{min}$. Various methods have been used to measure the strains in TRC and FRCM [19]. Strain gauges are inadequate since provide only local information. Extensometers are ideal to assess the alignment of the specimen and to avoid possible out-of-plane bending moment. The optimum set up would include four LVDTs placed on the opposite sides of the specimen. Photogrammetry can be another refined method that provides a complete overview of the crack formation in the specimen. This would be the ideal system of measurement but it becomes burdensome for large series of tests. The US Standards AC 434 [17] suggest to use an extensometer with a minimum gauge length of $50 \mathrm{~mm}$ that shall be adequate to at least include one significant crack. In this study the deformations were measured using an extensometer with a gauge length of $100 \mathrm{~mm}$ positioned in the central area of the specimens (Fig. 7). Being the dimension of the specimens $400 \times 40 \times 10 \mathrm{~mm}$, the distance

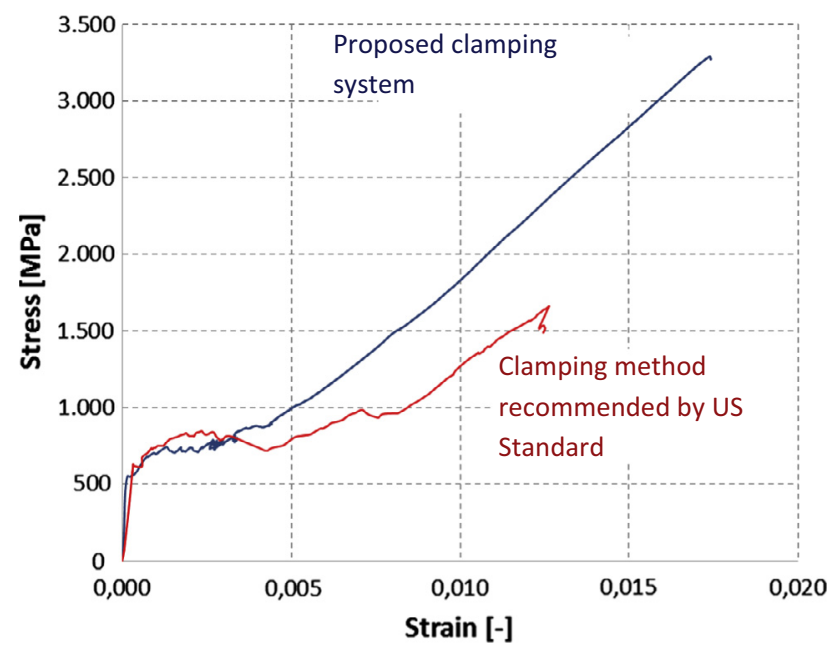

Fig. 5. Stress-Strain behavior: comparison between two clamping methods.

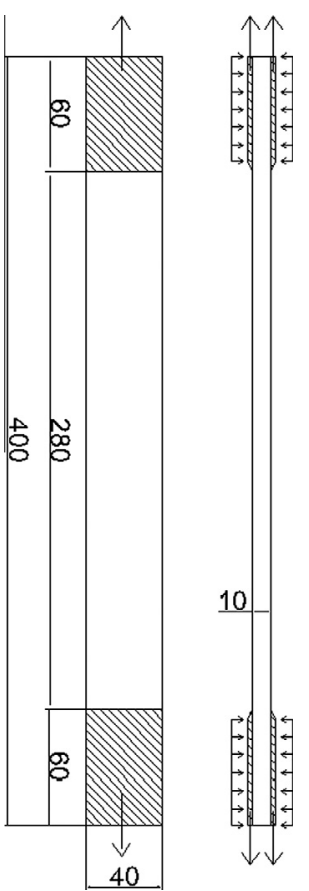

Fig. 6. FRCM specimens size. 


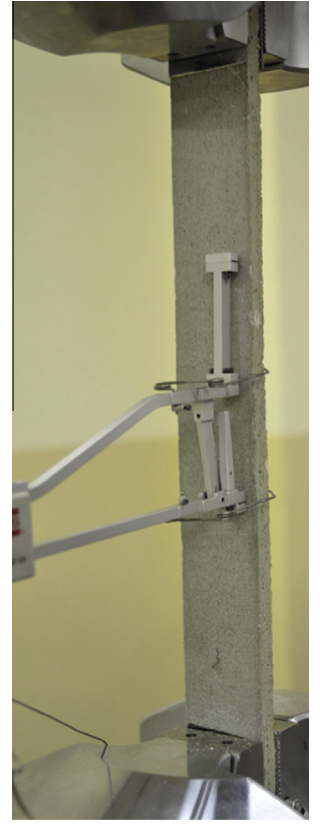

Fig. 7. Tensile test set-up.

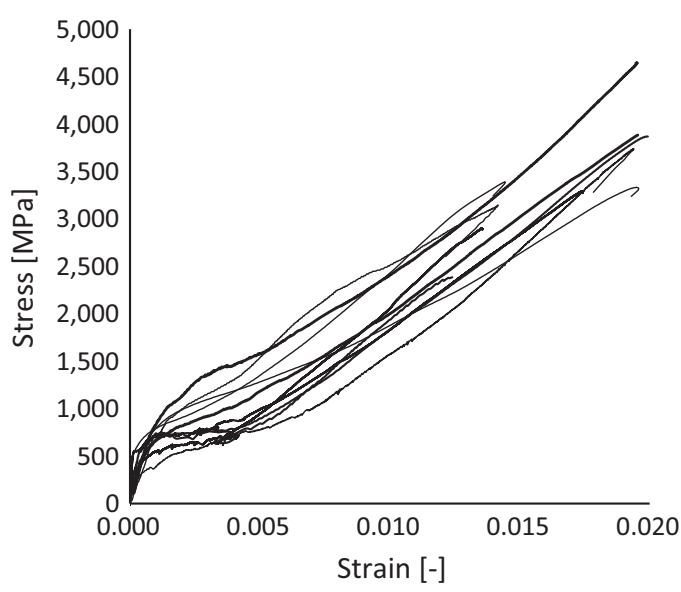

Fig. 8. Stress-strain curves for PBO-FRCM specimens.

between the two grips of the testing machine was $280 \mathrm{~mm}$. Therefore the extensometer gauge length of $100 \mathrm{~mm}$ covered about $1 / 3$ of the free surface of the specimen giving an adequate measurement of the strain field. This was checked by means of a detailed comparison with the displacement of the clamps.

\section{Tensile test: experimental results}

The results of tensile tests are here presented for the following materials: PBO1-FRCM, G-FRCM and C-FRCM.

\subsection{PBO1-FRCM}

Tensile tests on PBO1-FRCM specimens show a tri-linear behavior as in Fig. 1. In the first linear branch the specimen is uncracked and the slope reflects the elastic modulus of the cementitious mortar. Once the tensile strength of the mortar is reached (point $\mathrm{T}_{1}$ ) the force is transferred to the textile (second phase). In the third phase (starting from point $\mathrm{T}_{2}$ ) only the contribution of the textile is notice-able and the slope reflects the elastic modulus of the dry fibers.

As expected, the results show a large variability in particular for the localization of points $T_{1}$ and $T_{2}$. This phenomenon is mainly caused by two parameters: the non-regular dimensions of the specimen section (see Table 4) and the location of the first crack with respect to the extensometer [38]. As described in Chapter 2, the extensometer had a length of $100 \mathrm{~mm}$ and was located in the central part of the specimens. Therefore the cracks that appeared outside this interval could not be recorded.

A series of 23 tensile tests made with PBO-FRCM was tested. Fig. 8 shows the stress-strain behavior of some specimens. In Table 5 a summary of the results is reported. The parameters were derived dividing the loads by the section of the fabric. Only for the first phases, in which the mortar is un-cracked, tensile stress $\left(\sigma_{\mathrm{t} 1}^{*}\right)$ and elastic modulus $\left(E_{1}^{*}\right)$ were also referred to the composite cross section in order to compare the cracking tensile stress and the elastic modulus with the mortar properties. These values are reported in the last two columns in Table 5. The stress in the mortar at point $\mathrm{T}_{1}$ is 3.65 MPa that is lower but comparable to the nominal maxi-mum tensile strenght of the mortar (4.27 MPa).

The elastic modulus of the third phase $(215.7 \mathrm{GPa})$ is very similar to the elastic modulus of the dry PBO textile (216 GPa). Fig. 9 shows a comparison between the tensile test on PBO-FRCM with 4 rovings, and the dry $\mathrm{PBO}$ textile with 1,4 and 5 rovings.

The experimental results show a quite large variability, in particular for the elastic modulus of the second phases and the deformations corresponding to first and second points of transition. These variability could be caused by several factors: the irregularities of the cross section of the specimens, the

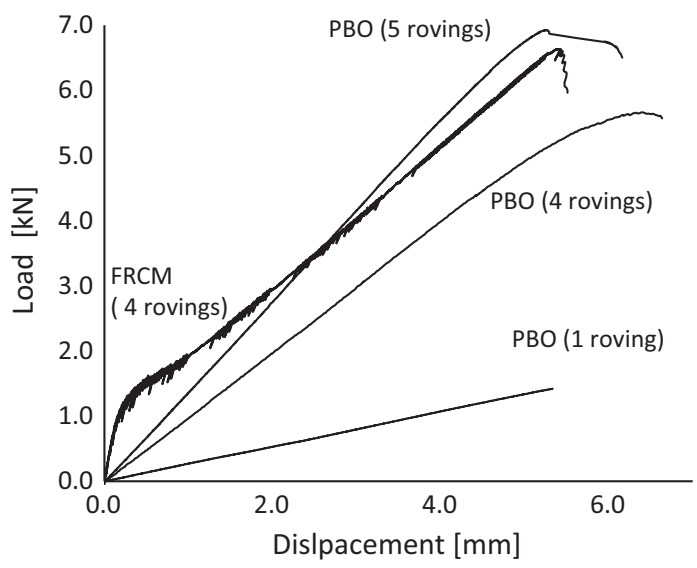

Fig. 9. Force-displacement curves for PBO-FRCM and dry PBO fibers (1 roving, 4 and 5 rovings).

Table 5

Tensile tests results on PBO-FRCM.

\begin{tabular}{|c|c|c|c|c|c|c|c|c|c|c|c|}
\hline & $E_{1}(\mathrm{GPa})$ & $E_{2}(\mathrm{GPa})$ & $E_{3}(\mathrm{GPa})$ & $\sigma_{\mathrm{t} 1}(\mathrm{MPa})$ & $\sigma_{\mathrm{t} 2}(\mathrm{MPa})$ & $\sigma_{\mathrm{u}}(\mathrm{MPa})$ & $\varepsilon_{\mathrm{t} 1}(\%)$ & $\varepsilon_{\mathrm{t} 2}(\%)$ & $\varepsilon_{\mathrm{u}}(\%)$ & $E_{1}^{*}(\mathrm{GPa})$ & $\sigma_{\mathrm{t} 1}^{*}(\mathrm{MPa})$ \\
\hline Average & 1180.8 & 75.7 & 215.8 & 890.2 & 1099.6 & 3316.4 & 0.08 & 0.50 & 1.69 & 4.84 & 3.65 \\
\hline Min value & 902.6 & 38.8 & 189.2 & 509.8 & 551.1 & 2485.1 & 0.04 & 0.24 & 1.27 & 3.70 & 2.09 \\
\hline Max value & 1612.8 & 122.4 & 250.0 & 1119.5 & 1640.6 & 4669.4 & 0.13 & 0.81 & 2.00 & 6.61 & 4.59 \\
\hline $\mathrm{CoV}[\%]$ & 19.6 & 33.1 & 9.2 & 15.2 & 12.6 & 14.0 & 30.90 & 33.70 & 18.20 & 19.60 & 15.20 \\
\hline
\end{tabular}



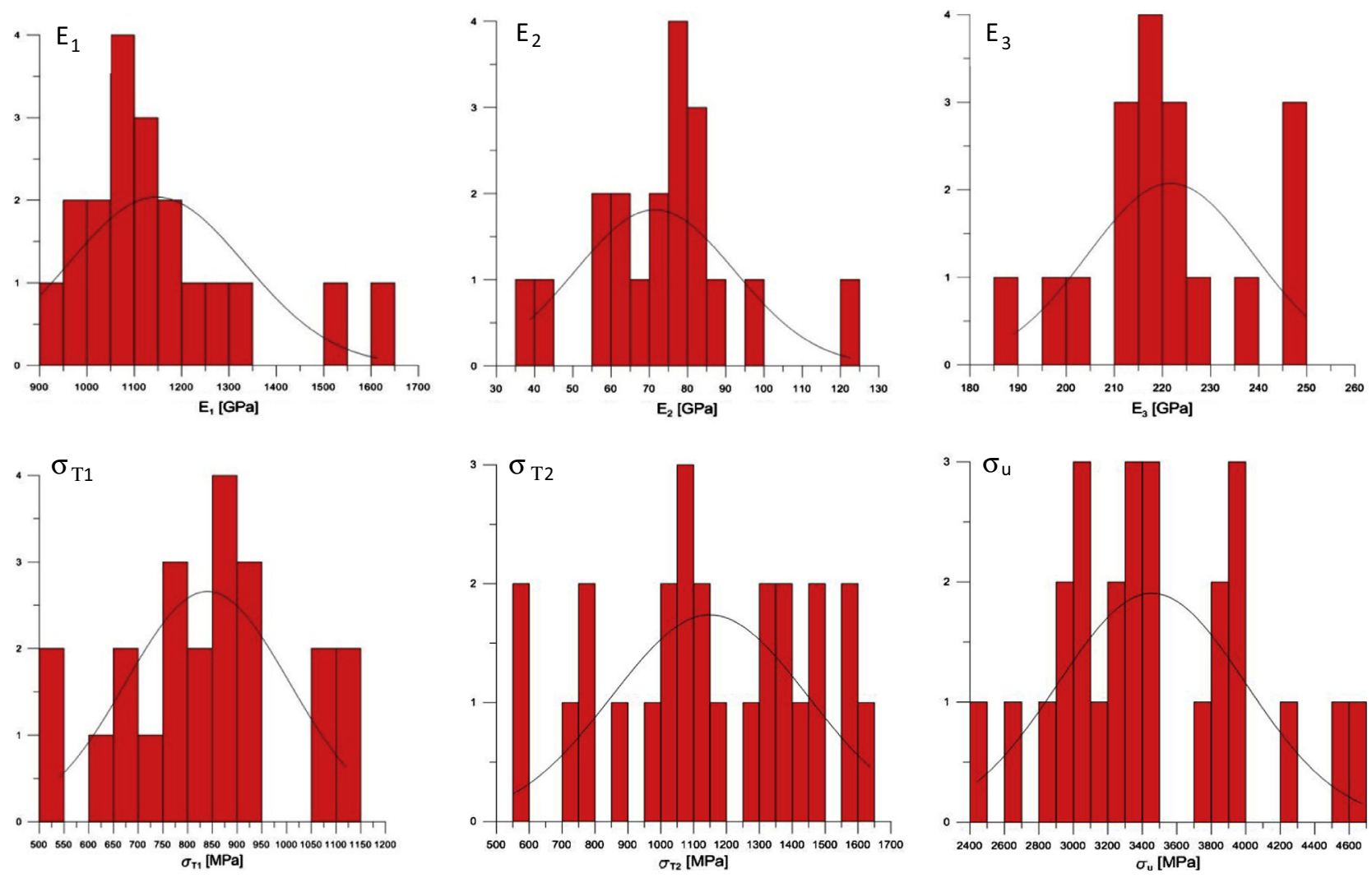

Fig. 10. PBO-FRCM: Statistical analysis of E1, E2 and E3, and stress in point $T 1, T 2$ and ultimate stress.

presence of micro-cracks invisible to the naked eye, the irregular position of the textile in the thickness and the localization of the first cracks with respect to the extensometer.

Fig. 10 shows a statistical analysis of these parameters.

Three further tensile tests were carried out applying cyclic loadings. The test set-up was the same as for monotonic tests while the cycles were applied in load steps of $0.2 \mathrm{kN}$ and displacement steps

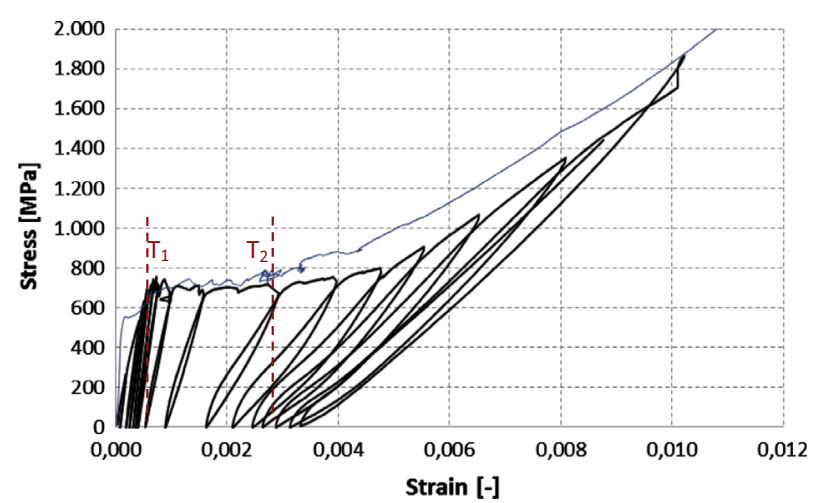

Fig. 11. Stress-strain curves, comparison between monotonic test and cycling test. equal to $0.1 \mathrm{~mm}$ in the cracking phase. Fig. 11 shows a stressstrain curve compared with a correspondent monotonic curve. A good correlation between the two curves is evident even if, as expected, the maximum load is lower than the average failure load

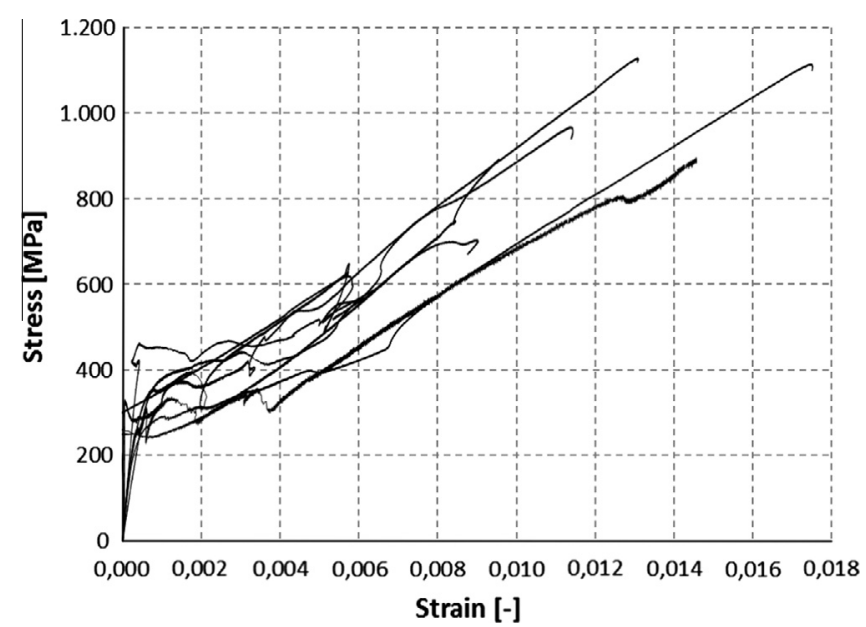

Fig. 12. Stress-strain curves for G-FRCM specimens.

Table 6

Load-Unload tests results on PBO1-FRCM.

\begin{tabular}{|c|c|c|c|c|c|c|c|c|}
\hline \multirow[t]{2}{*}{ Sample } & \multicolumn{2}{|c|}{ Stress (MPa) } & \multicolumn{2}{|c|}{ Residual displacement (mm) } & \multicolumn{2}{|c|}{ Residual strain (\%) } & \multicolumn{2}{|c|}{ Average Crack residual dimension ( $\mathrm{mm})$} \\
\hline & $\mathrm{T}_{2}$ & Collapse & $\mathrm{T}_{2}$ & Collapse & $\mathrm{T}_{2}$ & Collapse & $\mathrm{T}_{2}$ & Collapse \\
\hline PBO1-FRCM1 load/unload & 687.2 & 1838.7 & 0.53 & 1.20 & 0.19 & 0.38 & 0.088 & 0.12 \\
\hline PBO1-FRCM2 load/unload & 819.1 & 1535.7 & 0.47 & 1.57 & 0.17 & 0.27 & 0.067 & 0.17 \\
\hline PBO1-FRCM3 load/unload & 850.4 & 1843.9 & 0.56 & 1.48 & 0.20 & 0.53 & 0.062 & 0.16 \\
\hline Average & 785.6 & 1739.4 & 0.52 & 1.42 & 0.18 & 0.39 & 0.072 & 0.15 \\
\hline
\end{tabular}


Table 7

Tensile tests results on G-FRCM.

\begin{tabular}{|c|c|c|c|c|c|c|c|c|c|c|c|}
\hline & $E_{1}(\mathrm{GPa})$ & $E_{2}(\mathrm{GPa})$ & $E_{3}(\mathrm{GPa})$ & $\sigma_{\mathrm{t} 1}(\mathrm{MPa})$ & $\sigma_{\mathrm{t} 2}(\mathrm{MPa})$ & $\sigma_{\mathrm{u}}(\mathrm{MPa})$ & $\varepsilon_{\mathrm{t} 1}(\%)$ & $\varepsilon_{\mathrm{t} 2}(\%)$ & $\varepsilon_{\mathrm{u}}(\%)$ & $E_{1}^{*}(\mathrm{GPa})$ & $\sigma_{\mathrm{t} 1}^{*}(\mathrm{MPa})$ \\
\hline Average & 1310.16 & 32.33 & 64.22 & 460.05 & 431.11 & 872.17 & 0.045 & 0.38 & 0.69 & 5.89 & 2.07 \\
\hline Min value & 980.40 & 20.04 & 38.32 & 288.88 & 340.23 & 621.32 & 0.035 & 0.34 & 0.42 & 4.41 & 1.29 \\
\hline Max value & 2161.51 & 41.58 & 83.95 & 644.45 & 550.14 & 1127.78 & 0.091 & 0.46 & 1.10 & 9.73 & 2.90 \\
\hline $\mathrm{CoV}$ [\%] & 33.49 & 34.38 & 17.03 & 29.90 & 19.59 & 21.29 & 40.71 & 12.61 & 37.95 & 33.50 & 29.90 \\
\hline
\end{tabular}

of the monotonic tests. The three tests showed a percent reduction of the maximum load with respect to the average failure load of the monotonic tests respectively equal to $43.6 \%, 49.7 \%$ and $36.6 \%$.

The initial part of the reloading path, at least in the first cycles, is apparently similar to the elastic stiffness of the starting cycle. For higher loads the slope of the reloading path decreases. This aspect is reduced in the following cycles. The residual dimensions of the cracks after the un-loading cycle were measured at the second transition point $\left(\mathrm{T}_{2}\right)$ and at collapse analyzing the digital images and the residual displacements and strains recorded during the tests. Table 6 shows these values.

\subsection{G-FRCM}

Tensile tests on G-FRCM show mainly a bi-linear behavior since only in few tests a third phase is recognizable and in most of the tests the second and third phases are comparable (Fig. 12).

Table 7 shows the average tensile results of 17 tests on G-FRCM, the values reported were calculated as explained in the previous paragraph. The stress was calculated dividing the loads by the section of the fabric (Fig. 12). Even in this case the last two columns in Table 7 report the first elastic modulus and the stress corresponding to $\mathrm{T}_{1}$ calculated with reference to the mortar area.

The stiffness of the third phase ( $64.22 \mathrm{GPa}$ ) could be compared with the elastic modulus of the glass fiber grid (55.6 GPa).

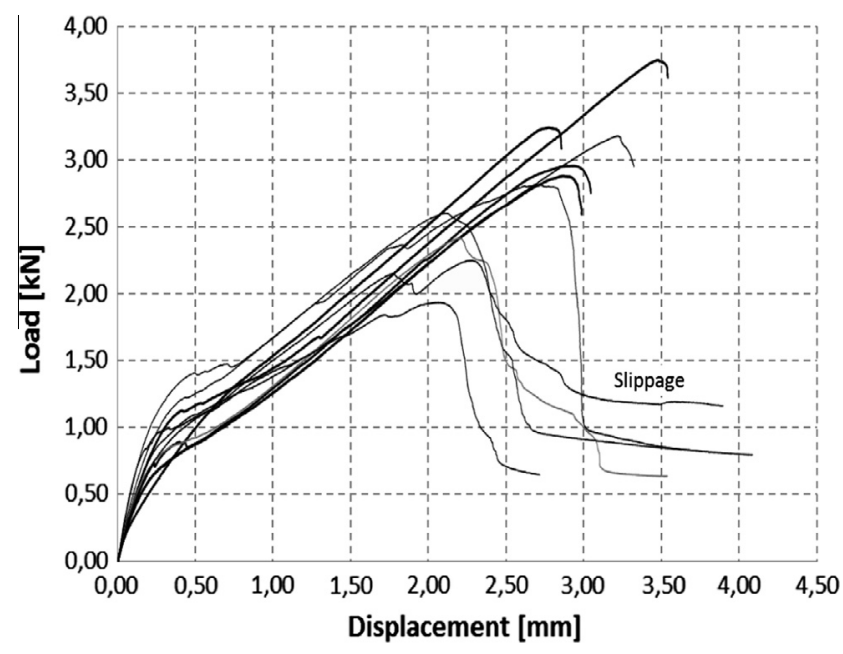

Fig. 13. Load-displacement curves for C-FRCM specimens.

\subsection{C-FRCM}

Tensile tests on C-FRCM show a tri-linear behavior like tests with PBO-FRCM. A phenomenon of slippage was noted in many tests (Fig. 13) due to problems of bond and impregnation between the mortar and the dry carbon fiber. Damage of carbon textile was observed close to the main cracks.

10 tests were carried out on C-FRCM and the stress-strain curves are reported in Fig. 13. Table 8 shows the tensile test results. The modulus of the third phase (186.42 GPa) was slightly lower than the one of the dry carbon textile (203 GPa) because of the phenomena of slippage between carbon fibers and mortar.

The load-displacement curves in Fig. 13 highlight the slippage phenomena that are not evident in the stress-strain plots. The slippage is represented in the decreasing last branch of some curves. This is not evident in Fig. 14 because the stress-strain curves are recorded by the extensometer that was removed just before the ultimate failure. This branch can indicate a fourth zone of the load-displacement curves as reported in [22]. This phenomenon was interpreted in [19] as a consequence of measuring the average strains along the entire height of the specimens and therefore including the pull-out effects.

Even in this case two tensile cyclic tests were carried out. The test set-up was the same of monotonic tests and the cycles were done at steps of $0.2 \mathrm{kN}$. Fig. 15 shows a stress-strain curve and a comparison with a corresponding monotonic curve showing a good

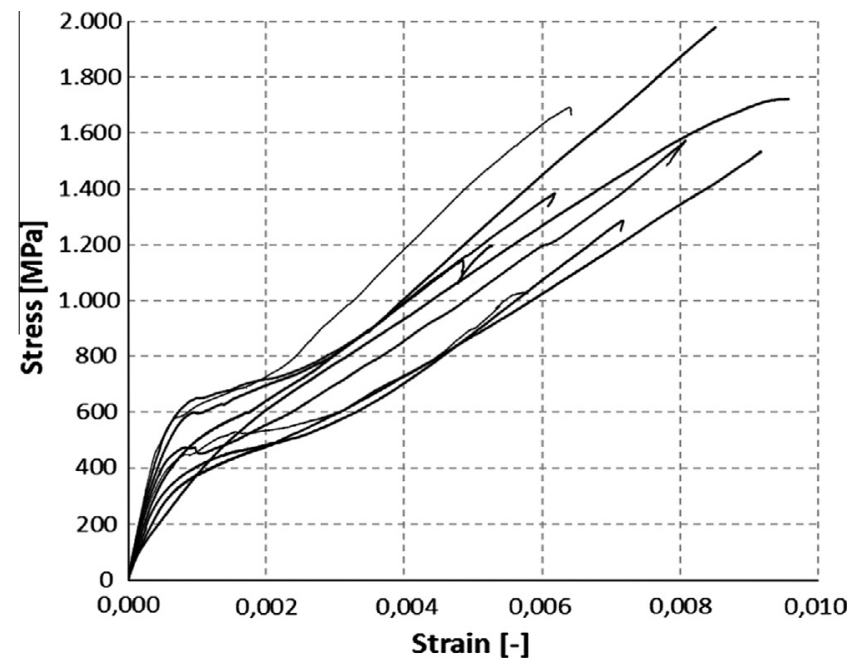

Fig. 14. Stress-strain curves for C-FRCM specimens.

Table 8

Tensile tests results on C-FRCM.

\begin{tabular}{|c|c|c|c|c|c|c|c|c|c|c|c|}
\hline & $E_{1}(\mathrm{GPa})$ & $E_{2}(\mathrm{GPa})$ & $E_{3}(\mathrm{GPa})$ & $\sigma_{\mathrm{t} 1}(\mathrm{MPa})$ & $\sigma_{\mathrm{t} 2}(\mathrm{MPa})$ & $\sigma_{\mathrm{u}}(\mathrm{MPa})$ & $\varepsilon_{\mathrm{t} 1}(\%)$ & $\varepsilon_{\mathrm{t} 2}(\%)$ & $\varepsilon_{\mathrm{u}}(\%)$ & $E_{1}^{*}(\mathrm{GPa})$ & $\sigma_{\mathrm{t} 1}^{*}(\mathrm{MPa})$ \\
\hline Average & 1102.2 & 68.23 & 186.42 & 481.72 & 619.56 & 1492.02 & 0.06 & 0.24 & 0.74 & 4.96 & 2.02 \\
\hline Min value & 802.4 & 42.44 & 136.10 & 332.07 & 480.00 & 1031.91 & 0.05 & 0.17 & 0.52 & 3.37 & 1.39 \\
\hline Max value & 1519.1 & 95.02 & 245.00 & 614.74 & 748.90 & 1994.68 & 0.07 & 0.31 & 0.99 & 6.38 & 2.58 \\
\hline $\mathrm{CoV}[\%]$ & 17.5 & 28.28 & 22.17 & 21.42 & 19.12 & 18.82 & 12.76 & 20.04 & 21.01 & 17.59 & 21.42 \\
\hline
\end{tabular}




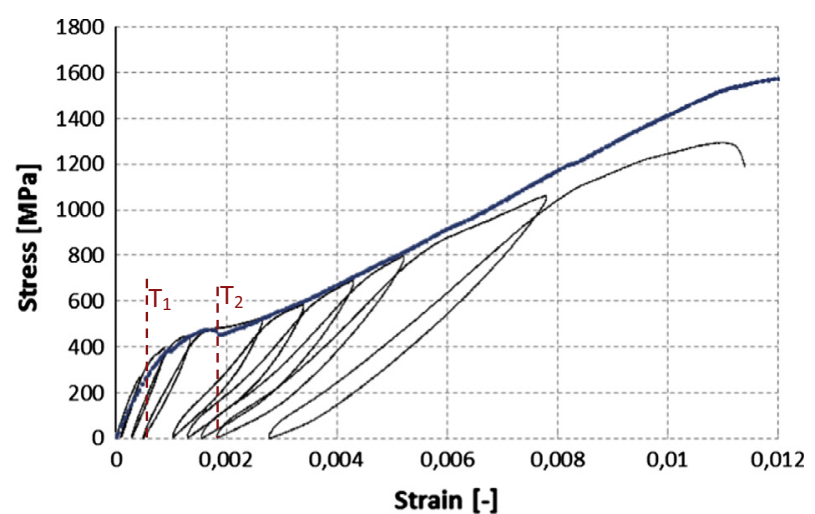

Fig. 15. Stress-strain curves, comparison between monotonic test and load-unload cycling test.

correlation. At the second transition point $\left(\mathrm{T}_{2}\right)$ and at collapse the residual dimensions of the cracks after the un-load cycle were measured analyzing the digital images and the residual displacements and strains recorded during the tests. Table 9 shows these values. The two tests showed a percent reduction of the maximum load respect to the average failure load of the monotonic tests equal to $12.8 \%$ and $7.8 \%$ respectively.

Fig. 16 shows a comparison of tensile tests results on PBO-FRCM, G-FRCM and C-FRCM materials. The stiffness of the first and second phases of the three materials are comparable. Instead there are many differences in the third phase, due to the different elastic moduli and tensile strengths of the fibers. The ultimate strength of PBO-FRCM is the highest but the envelope is signifi-cantly large. On the contrary the small variability of the results for G- FRCM is correlated to the lowest mechanical properties.

Table 10 reports a comparison between the maximum stresses and strains reached in tensile tests on FRCM materials and on the dry fibers and the strains reached at the end of each phase with respect to the maximum strain. The results highlight a good correlation between the strength of FRCM materials and its components. This indicates that the stresses are completely transmitted from the matrix to the textile. The results of C-FRCM are lower because of the slippage phenomena developed between matrix and dry fibers. The ratio between the strains at the end of the first and sec-ond phases show that the second phase is characterized by the properties of each material but this value increases for greater distances between the rovings in the weft direction in the textile. Finally, the ratio of the average strains at the end of the second phase and at failure are values close to 3.3. This consideration, even if limited to the present investigation, could be included in possible guidelines for FRCM.

\section{Crack spacing measurements}

The crack development throughout the loading cycle of the tensile tests was recorded by digital images of the specimens at regular load-deformation increment intervals. The trends of the crack

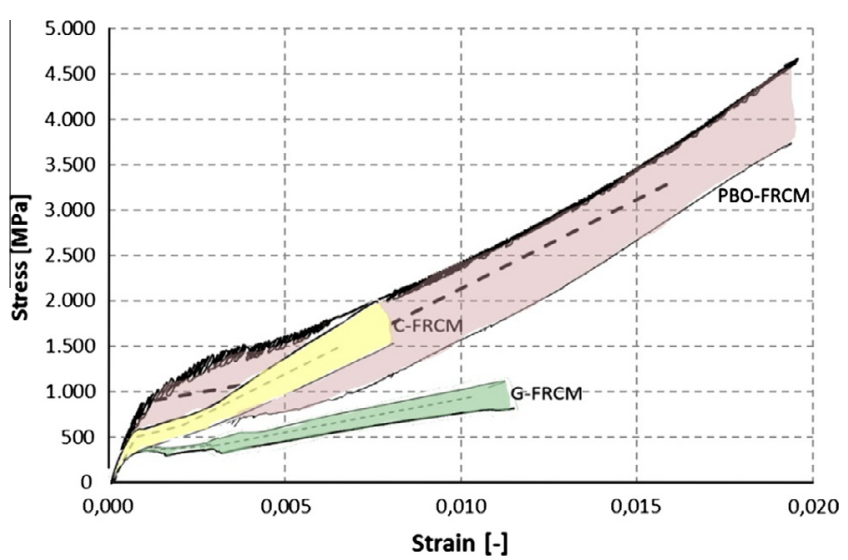

Fig. 16. Stress-strain curves: PBO-FRCM, C-FRCM, G-FRCM with average values (dashed lines).

spacing are analyzed in relation to the stress level reached. The crack spacing was reduced in the first part of the test and then it reached a level that is called the "saturation crack spacing" [22]. After this point, there was an increase of the size of the cracks, without formation of further cracks. For PBO-FRCM samples (Fig. 17) the saturation crack spacing was variable from $19 \mathrm{~mm}$ to 25 $\mathrm{mm}$ while for G-FRCM (Fig. 18) was approximately of $50 \mathrm{~mm}$ and for C-FRCM (Fig. 19) it was variable from $26 \mathrm{~mm}$ to $30 \mathrm{~mm}$. In order to better analyze the cracking phase and facilitate the comparisons, in these figures the stresses are calculated with respect to the cross section area of the mortar for each specific specimen. An anomalous point is visible in Fig. 17. One of the specimens for a stress between 2.0 and $2.5 \mathrm{MPa}$ presented an increase of the crack spacing during loading. This is due to the fact that in the first phase the location of the cracks is not homogeneous on the specimen. In this particular case the crack spacing between the first and second cracks was equal to $55 \mathrm{~mm}$. Afterword the third crack appeared at a distance of $85 \mathrm{~mm}$ from the first. So the average crack spacing at this stress level became equal to $70 \mathrm{~mm}$.

Fig. 20 shows the trend of the crack size with respect to the reached deformation level. A typical curve is shown for each material. In PBO-FRCM specimens, when the level of saturation crack spacing was reached (with a deformation equal to 0.01 ), the crack increase up to a maximum value before the collapse which varies between $0.29 \mathrm{~mm}$ and $0.50 \mathrm{~mm}$. In C-FRCM a similar behavior could be highlighted, and the size of the cracks before the collapse varies between $0.30 \mathrm{~mm}$ and $0.45 \mathrm{~mm}$. In G-FRCM the behavior was similar, but the level of saturation crack spacing is reached for a deformation of 0.0015 . The maximum cracks size was variable from $0.63 \mathrm{~mm}$ to $0.92 \mathrm{~mm}$.

These results show how the different size of the fiber grids and the geometries influenced the cracks propagation and their maximum dimensions. The PBO grid had a dimension of $20 \mathrm{~mm}$ in the weft direction and this caused a saturation crack spacing of about $22 \mathrm{~mm}$. On the contrary this cannot be the explanation both in the case of C-FRCM specimens where the grid is $10 \mathrm{~mm}$ against a

Table 9

Load-unload tests results on C-FRCM.

\begin{tabular}{|c|c|c|c|c|c|c|c|c|}
\hline \multirow[t]{2}{*}{ Sample } & \multicolumn{2}{|c|}{ Stress (MPa) } & \multicolumn{2}{|c|}{ Residual displacement (mm) } & \multicolumn{2}{|c|}{ Residual strain (\%) } & \multicolumn{2}{|c|}{ Average crack residual dimension ( $\mathrm{mm})$} \\
\hline & $\mathrm{T}_{2}$ & Collapse & $\mathrm{T}_{2}$ & Collapse & $\mathrm{T}_{2}$ & Collapse & $\mathrm{T}_{2}$ & Collapse \\
\hline C-FRCM1 load/unload & 759.2 & 1586.8 & 0.21 & 0.49 & 0.087 & 0.21 & 0.052 & 0.096 \\
\hline C-FRCM2 load/unload & 570.3 & 1048.3 & 0.35 & 0.67 & 0.147 & 0.29 & 0.088 & 0.116 \\
\hline Average & 664.7 & 1317.5 & 0.28 & 0.58 & 0.117 & 0.26 & 0.070 & 0.063 \\
\hline
\end{tabular}


Table 10

Comparison between stresses and strains reached in different phase of the tensile tests.

\begin{tabular}{|c|c|c|c|c|}
\hline Materials & $\sigma_{\mathrm{FRCM}} / \sigma_{\text {dry fibers }}$ & $\varepsilon_{\mathrm{FRCM}} / \varepsilon_{\text {dry fibers }}$ & $\varepsilon_{\mathrm{FRCM}}$ phase $2 / \varepsilon_{\mathrm{FRCM}}$ phase 1 & $\varepsilon_{\mathrm{FRCM} \max } / \varepsilon_{\mathrm{FRCM}}$ phase 2 \\
\hline PBO-1 & 0.97 & 0.85 & 6.25 & 3.38 \\
\hline G & 0.89 & 0.81 & 8.33 & 3.48 \\
\hline C & 0.78 & 0.82 & 3.83 & 3.22 \\
\hline
\end{tabular}

saturation crack spacing of $28 \mathrm{~mm}$ and in the case of G-FRCM specimens with a grid of $15 \mathrm{~mm}$ against a saturation crack spacing of approximately $50 \mathrm{~mm}$. Further investigation is needed to clarify this aspects connected to the grid geometry. For example, techniques as thermography could be adopted to study the cracks location with respect to the transversal yarns geometry.

\section{Mechanical properties of FRCM systems applied to a brick}

The behavior of the FRCM system applied on a brick substrate was investigated to analyze both the adherence between the reinforced system and the substrate and between the dry textile and the cementitious mortar. The experimental campaign was developed on different FRCM materials: PBO2-FRCM, G-FRCM, C-FRCM and PBO-G-FRCM.

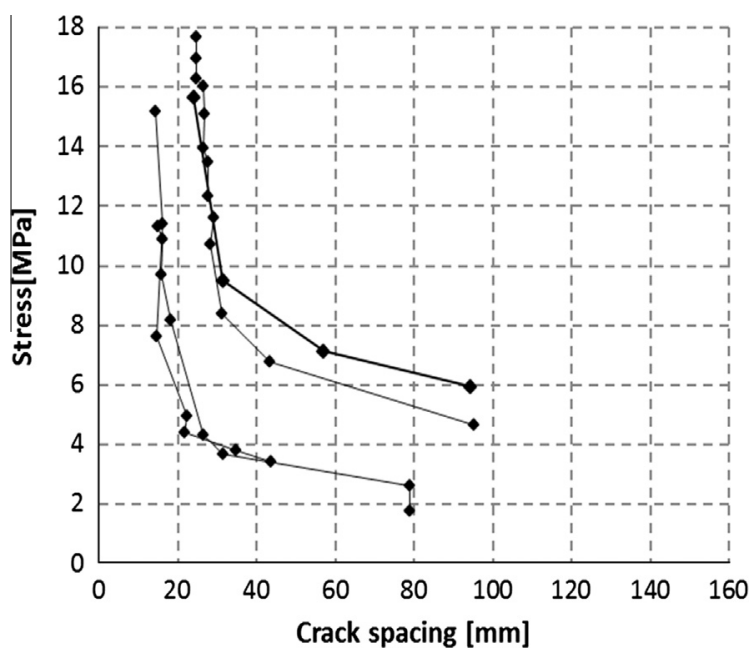

Fig. 17. Crack spacing vs stress. PBO-FRCM specimens.

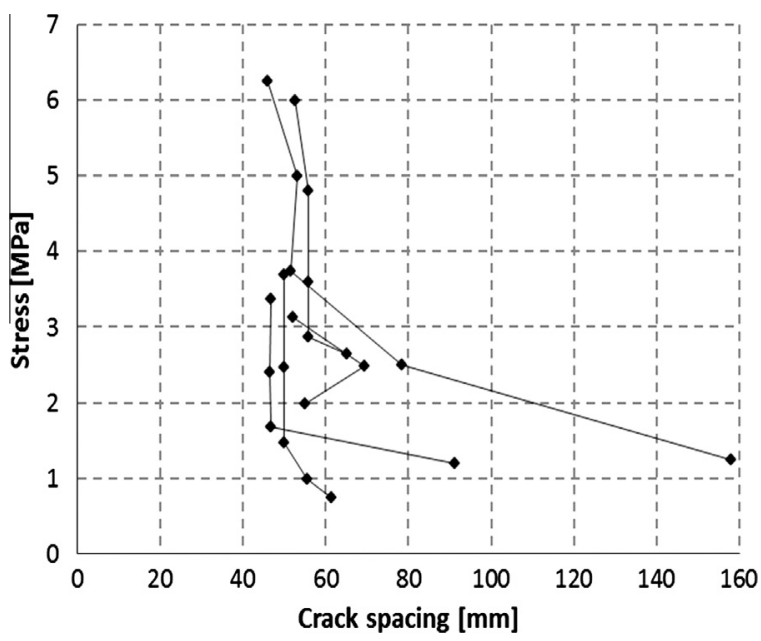

Fig. 18. Crack spacing vs stress. G-FRCM specimens.
Two different types of bricks were used: the PBO2-FRCM, PBOG-FRCM and C-FRCM were applied on bricks with a compressive strength of $20.8 \mathrm{MPa}$ [33] while the G-FRCM was applied on bricks with a compressive strength of $68.8 \mathrm{MPa}$ [27]. The pull-off resistance of this single brick used with G-FRCM was equal to 3.1 MPa. The large difference in the compressive strength of the bricks was motivated by the need to validate the tests with very different masonry substrates.

\subsection{Push-pull double lap tests}

Many methods have been developed to analyze the bond between reinforced materials (FRP and FRCM) applied on concrete or masonry substrates. The experimental set-ups include single

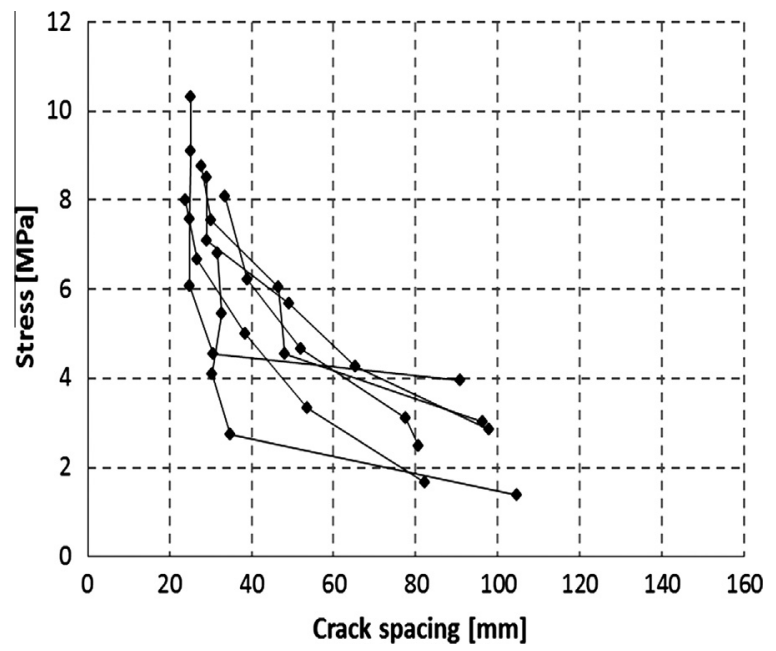

Fig. 19. Crack spacing vs stress. C-FRCM specimens.

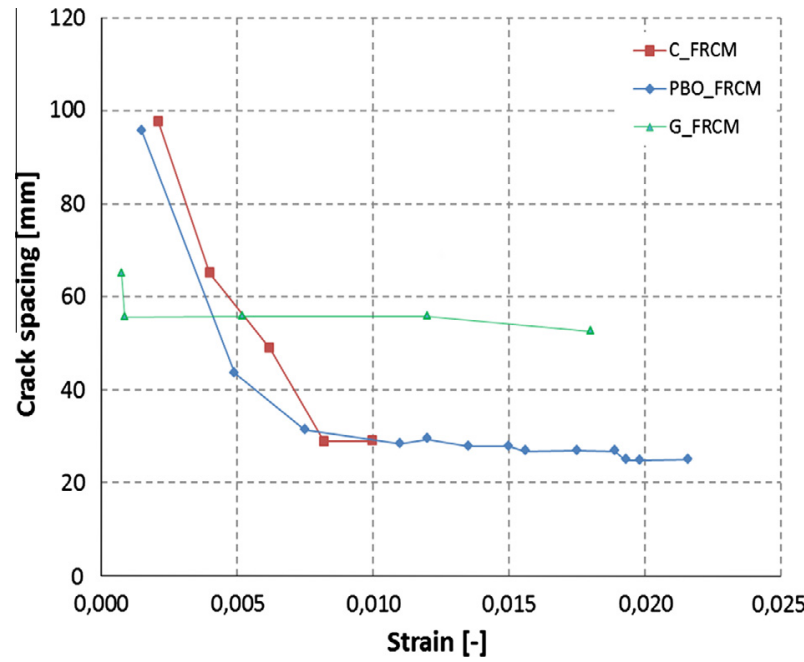

Fig. 20. Comparison of Carbon, PBO1 and Glass FRCM. Crack size vs strain 
$[23,24,36]$ or double laps $[4,24-26,37]$ push-pull shear tests. In order to avoid eccentricity phenomena and to verify the efficiency of the methodology, a double lap set-up was preferred in this work. A recent wide experimental campaign on masonry, detailed in [24], demonstrated that this testing set up is easy, economic and reliable.

An even distribution of the load between the two laps may be usually assumed. This could be verified in each test applying two instruments on the opposite sides of the bricks but with extra costs. During all the tests great attention was paid to verify the symmetry and the similar behavior of the two laps during the loading.

The testing rig for double-lap experiments was made with a steel frame composed of two transversal beams connected by four bars (Fig. 21). In order to minimize the effects of possible misalignments a spherical joint was positioned in the upper part of the rig. To guarantee even distribution of the load on the composite strips, the textile was placed around a cylinder with a diameter equal to the thickness of the brick and the relevant mortar. Two Teflon sheets were used to avoid friction and facilitate the even distribution of the load.

Two different geometries of the reinforcements were considered: glass fiber grids were bonded to two opposite sides of a single brick [27]. On the contrary carbon, PBO and PBO-G grids were bonded on a specimen composed of three bricks and two mortar joints.

Different bond lengths and widths were considered in order to investigate the effect of these parameters on the debonding strength and failure modes. Table 11 shows the layout of the experimental tests.
A special test frame was designed and realized to perform the tests (Fig. 21).

\subsection{Experimental results}

The results of the tested series of specimens are here reported in terms of load-displacement curves. In particular the total applied load is considered while the relative displacement of the grips of the testing machine was recorded deducing the elongation of the dry strip in the unbounded textile (Fig. 21). The stiffness of the setup was verified and its deformability was evaluated negligible.

\section{- G-FRCM}

As expected, the bond length had an influence both on the failure load and on the failure mechanism. The failure load increased with the bond length. Short reinforcements (50 and $100 \mathrm{~mm}$ ) showed grid slippage at loads smaller than the tensile failure of the glass fibers (Fig. 26a). On the contrary, for longer bond lengths a tensile failure of the glass fibers grid was experienced. No debonding of the FRCM system from the substrate was detected in all specimens. Among the tested lengths $150 \mathrm{~mm}$ provides the best results, with an average failure load equal to $4.06 \mathrm{kN}$ (Table 12).

In Fig. 22 a comparison of the experimental load-displacement curves obtained for different bond lengths is represented. The differences in the failure modes and in the maximum loads are reported in Table 12 for the G-FRCM specimens. The average ultimate values vary from $1.0 \mathrm{kN}$ for a bond length of $50 \mathrm{~mm}$ to $4.1 \mathrm{kN}$ for a bond length of $150 \mathrm{~mm}$.
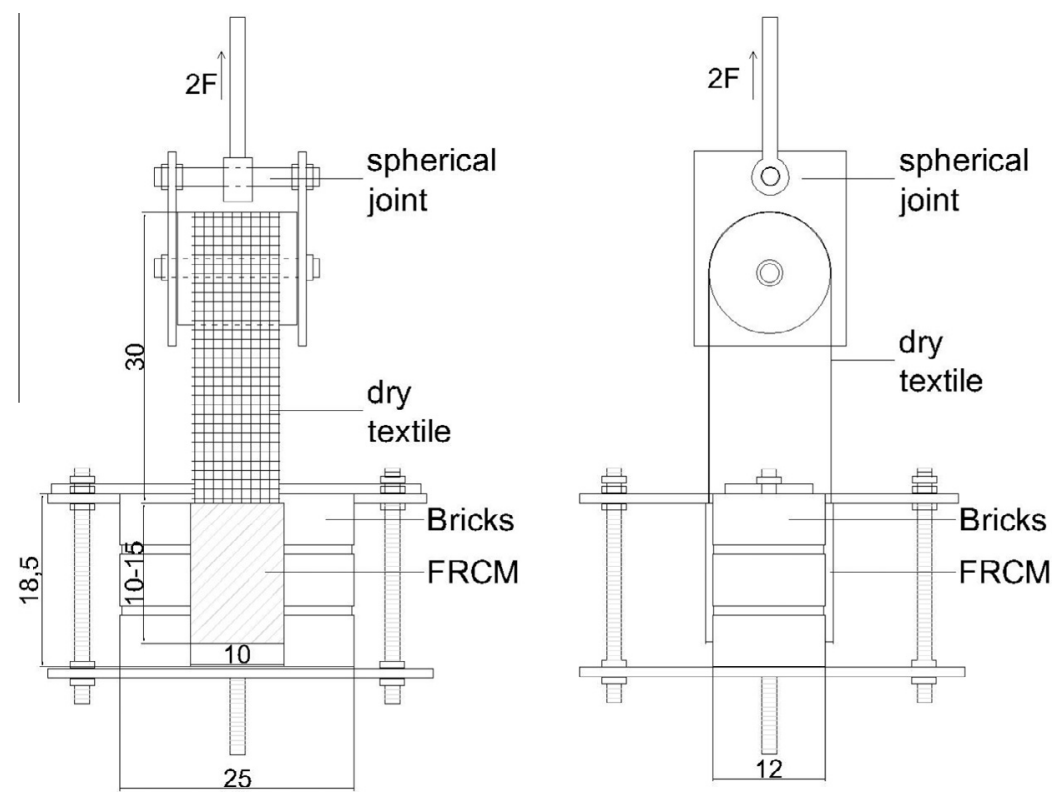

Fig. 21. Push-pull double lap tests set up (the measures are expressed in $\mathrm{cm}$ ).

Table 11

Geometry of double lap tests.

\begin{tabular}{|c|c|c|c|c|c|}
\hline Reinforcement type & \multicolumn{3}{|c|}{ Bond length (mm) } & Reinforcement width (mm) & Substrate \\
\hline G-FRCM & $50(5)$ & $100(5)$ & $150(5)$ & 50 (3 yarns) & Single brick \\
\hline PBO2-FRCM & - & $100(3)$ & $150(4)$ & 100 (7 rovings) & Three bricks \\
\hline C-FRCM & - & $100(3)$ & $150(4)$ & 100 (11 rovings) & Three bricks \\
\hline PBO-G-FRCM & - & $100(3)$ & $150(4)$ & 100 (7 rovings) & Three bricks \\
\hline
\end{tabular}

Note: Within brackets \# of samples. 
Table 12

Main experimental results of push-pull tests.

\begin{tabular}{|c|c|c|c|c|c|c|c|c|}
\hline \multirow[t]{2}{*}{ Reinf. type } & \multirow{2}{*}{$\begin{array}{l}\text { Bond } \\
\text { length } \\
(\mathrm{mm})\end{array}$} & \multicolumn{2}{|c|}{$\begin{array}{l}\text { Initial stiffness }(\mathrm{N} / \\
\mathrm{mm})\end{array}$} & \multicolumn{2}{|c|}{ Failure load $(\mathrm{kN})^{\mathrm{a}}$} & \multirow[t]{2}{*}{$\begin{array}{l}\text { Stress in yarns at } \\
\text { failure }(\mathrm{MPa})^{\mathrm{b}}\end{array}$} & \multirow{2}{*}{$\begin{array}{l}\text { Textile stress/ } \\
\text { textile strength } \\
(\%)\end{array}$} & \multirow[t]{2}{*}{ Failure mode } \\
\hline & & Average & $\begin{array}{l}\text { Standard } \\
\text { deviation }\end{array}$ & Average & $\begin{array}{l}\text { Standard } \\
\text { deviation }\end{array}$ & & & \\
\hline \multirow[t]{3}{*}{ G-FRCM } & 50 & 697 & 63.7 & 1.06 & 0.17 & 196.2 & 16.3 & Slippage of the grid \\
\hline & 100 & 644 & 17.2 & 2.63 & 0.17 & 487.0 & 58.4 & $\begin{array}{l}\text { Slippage and subsequent partial failure of the } \\
\text { grid }\end{array}$ \\
\hline & 150 & 670 & 64.4 & 4.06 & 0.55 & 751.8 & 62.6 & Tensile failure of the grid \\
\hline \multirow[t]{2}{*}{ PBO2-FRCM } & 100 & 1042 & 25.1 & 7.83 & 0.69 & 2542.2 & 80.0 & Partial fiber failure in weft and warp directions \\
\hline & 150 & 739 & 155.4 & 7.56 & 1.07 & 2454.5 & 77.3 & \\
\hline \multirow[t]{2}{*}{ C-FRCM } & 100 & 1703 & 152.9 & 10.19 & 0.31 & 1102.8 & 57.6 & $\begin{array}{l}\text { Partial fiber failure in weft and warp directions } \\
\text { and subsequent slippage of the grid }\end{array}$ \\
\hline & 150 & 1504 & 289.2 & 10.42 & 0.55 & 1127.7 & 59.0 & \\
\hline \multirow[t]{2}{*}{ PBO-G-FRCM } & 100 & 680 & 71.5 & 4.26 & 0.40 & 1776.6 & 58.9 & $\begin{array}{l}\text { Complete tensile failure of the glass fibers and } \\
\text { partial failure of the PBO fibers }\end{array}$ \\
\hline & 150 & 701 & 37.7 & 4.64 & 0.76 & 1933.3 & 66.3 & \\
\hline
\end{tabular}

a Total load applied to the specimen.

b Theoretical stress assuming a uniform distribution in the yarns.

\section{- PBO2-FRCM}

The tests on PBO2-FRCM samples showed a small influence of the bond length ( 100 and $150 \mathrm{~mm}$ ) both on the failure mechanism and load. The collapse was not abrupt with sudden breaking of all the fibers but it was characterized by a progressive failure of the rovings.

First of all the rovings in the weft direction collapsed, after that also the rovings in the warp direction gradually failed (Fig. 26b). The rovings in the external part of the grid are subjected to greater stresses. No slippage was observed between the grid and the cementitious matrix. In Fig. 23 a comparison of the experimental load-displacement curves obtained for different bond lengths is represented. The main experimental results are reported in Table 12.

\section{- C-FRCM}

Even the tests on C-FRCM samples showed a small influence of the bond length (100 and $150 \mathrm{~mm}$ ) both on failure mechanism and load. The failure mode presented a slippage located between the grid and the cementitious mortar after the a partial failure of the fibers in weft and warp directions (Fig. 26c). The collapse was not abrupt including all the fibers but it was characterized by a progressive failure of the rovings similar to the failure mode analyzed for PBO2-FRCM.

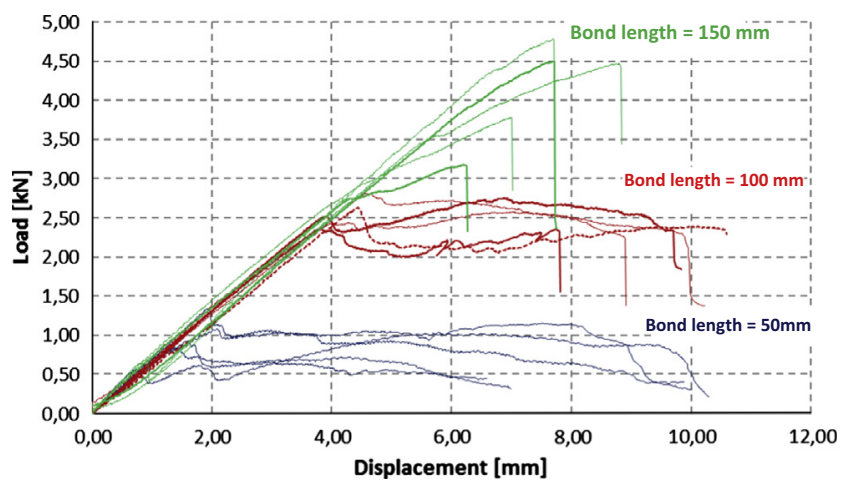

Fig. 22. Load-displacement curves for G-FRCM samples.
In Fig. 24 a comparison of the experimental load-displacement curves obtained at different bond lengths is represented. In Table 12 the main experimental results are reported. The slippage phenomena are difficult to identify in the load-displacement curves because the fiber-matrix slip occurs during the collapse of the system, after the partial fiber failure in weft and warp directions.

\section{- PBO-G-FRCM}

The tests on PBO-G-FRCM samples do not show an influence of the bond length (100 and $150 \mathrm{~mm}$ ) on failure mechanism or failure load. The failure mode showed first of all the collapse of the glass fibers at relatively low load and after that a gradual failure of the PBO fibers in the weft and warp directions was experienced (Fig. 26d). No slippage was observed between grid and cementi-tious mortar.

In Fig. 25 a comparison of the experimental load-displacement curves obtained for different bond lengths is represented. In Table 12 the main experimental results are reported.

The experimental results showed two main failure modes: in CFRCM specimens a failure in the fiber-matrix interface and the slippage of the grid in the mortar layer, in PBO-FRCM a partial failure of the fibers in weft and warp directions without slip between fibers and mortar. The tests carried out on G-FRCM showed the importance of the bond length in the occurrence of slippage

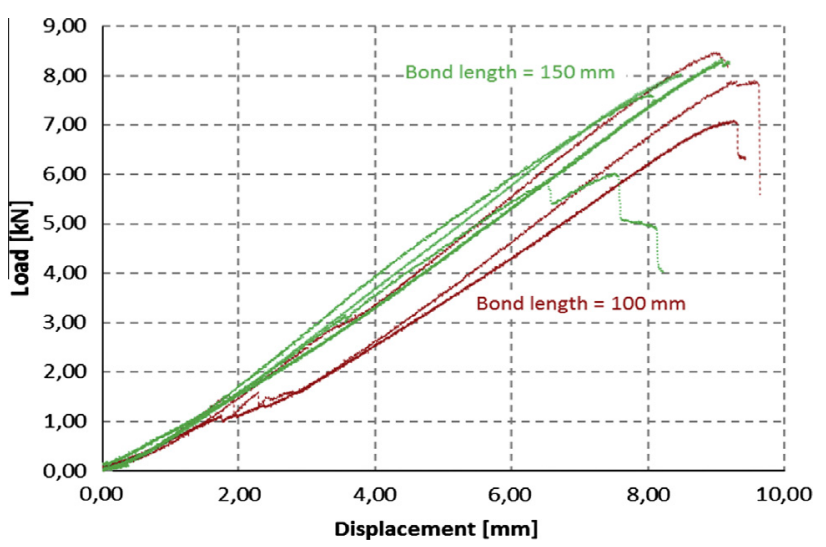

Fig. 23. Load-displacement curves for PBO2-FRCM samples. 


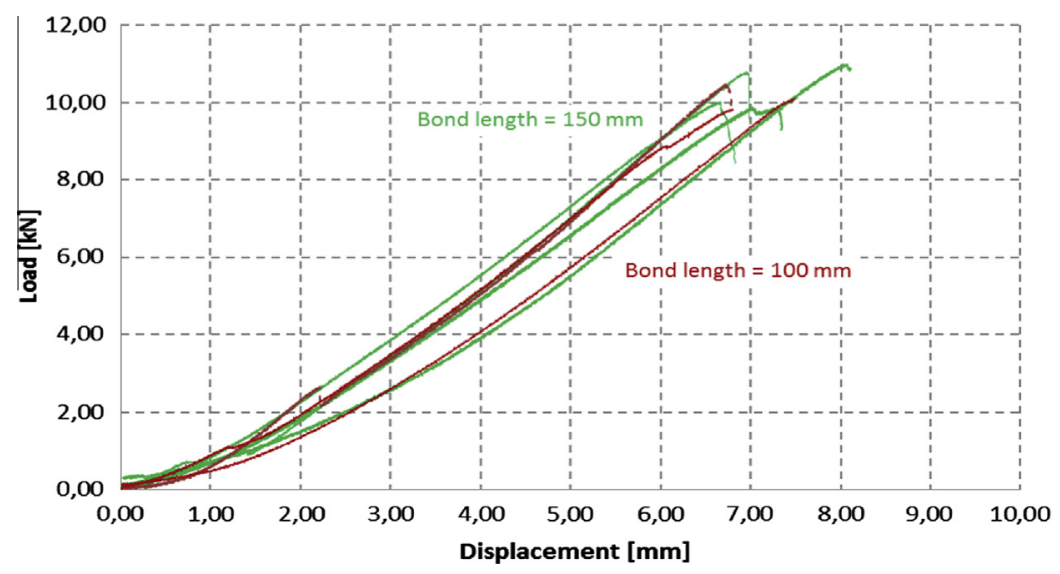

Fig. 24. Load-displacement curves for C-FRCM samples.

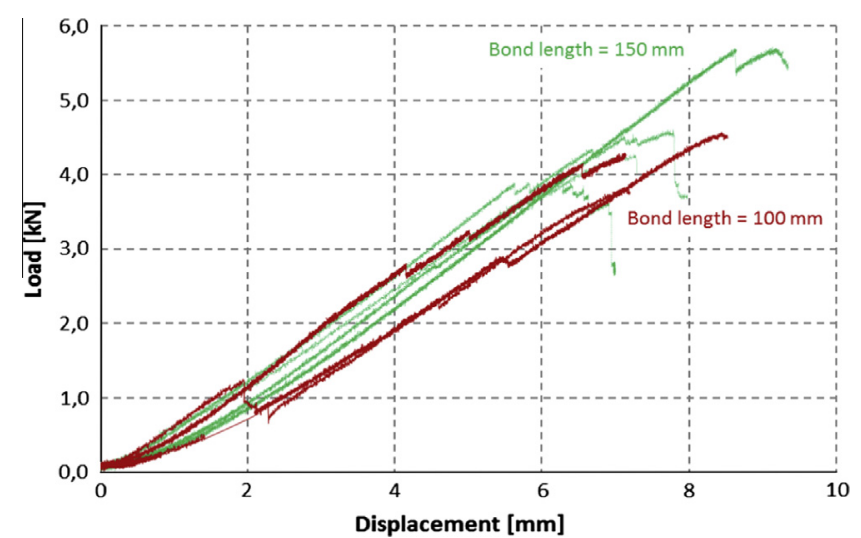

Fig. 25. Load-displacement curves - PBO-G-FRCM samples.

phenomena. For bond length equal to $150 \mathrm{~mm}$ the textile failure occurred, in the other cases slippage phenomena were detected.

In Table 12 the theoretical ultimate stress of the fibers assuming a uniform distribution in the yarn is also reported together with the ratio of the stress in the yarns with the tensile strength. These were calculated assuming a uniform distribution of the stresses in the yarns. This is an evident approximation but permits to estimate the ratio of the stress at failure against the ultimate strength of the fibers. All the failures detected in the experiments included only part of the fibers in the yarns for the so-called telescopic effects. Another factor that should be considered is the different area of influence of the rovings closer to the longitudinal edges. The width of the matrix layer is larger than the width of the textile of about 20 $\mathrm{mm}$ per side, so the area of influence of the external rovings is greater with respect to the internal ones.

It is known that a cement matrix is not ideal to impregnate filaments. The external filaments in a roving are in direct contact with the matrix and tightly bonded, while the internal filaments in the core of the yarn are not in direct contact with matrix and can slip more easily because of the low friction between the fibers.

Peled et al. [28], Soranakom and Mobasher [29] and Andic-Cakir et al. [30] presented a similar model to simulate the roving as a cylindrical structure comprised of concentric rings, each one composed of several filaments (Fig. 27). The failure mode of the filaments in the sleeve is the fracture while the internal filaments present a slippage due to the pull-out force.

This telescopic mode of pull-out [31] is influenced by the cement penetrability, the geometry of the reinforcement, the presence of a coating and the level of friction between the fibers in each yarn. The last can vary with the different qualities of the fibers. In particular it is believed that it is significant in the case of carbon fibers and that the PBO-FRCM specimens present a better bonding and a better stress transfer between matrix and filaments than the carbon or glass fibers. The PBO textile presents a geometry that facilitates the penetration of the mortar in the grid and an high friction level between the filaments due to the physical and chemical properties of the material.
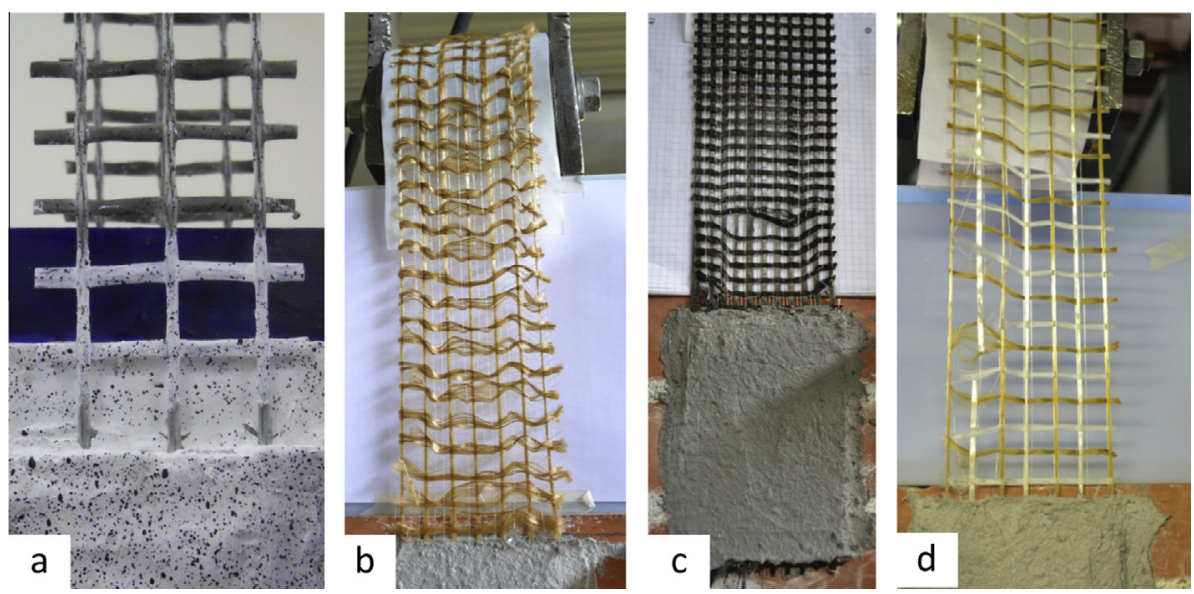

Fig. 26. Failure mode of push-pull double lap tests: (a) G-FRCM sample (bond length equal to 50 mm); (b) PBO2-FRCM; (c) C-FRCM; (d) PBO-G-FRCM. 

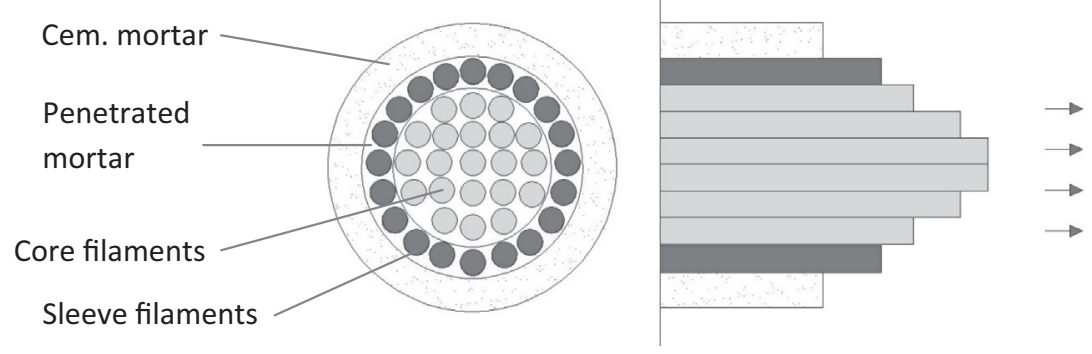

Fig. 27. Telescopic behavior: idealization of a roving embedded in the mortar [31].
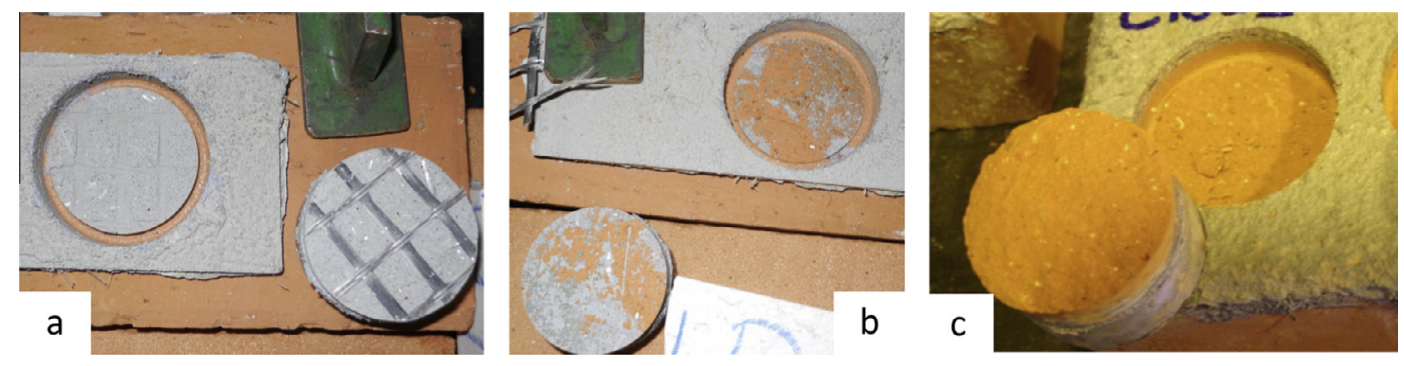

Fig. 28. Failure mode of pull-off tests: (a) G-FRCM sample mode (c); (b) G-FRCM sample mode (b); (c) C-FRCM mode (a).

Table 13

Average results of pull-off tests.

\begin{tabular}{|c|c|c|c|c|c|}
\hline & Reinforcement type & \# Tests & Maximum load (kN) & Maximum stress (MPa) & Failure mode \\
\hline \multirow[t]{2}{*}{ (1) } & G-FRCM & 2 & 2.9 & 1.48 & (c) Interface mortar-textile \\
\hline & & 3 & 2.6 & 1.34 & (b) Interface substrate-composite \\
\hline (2) & PBO2-FRCM & 6 & 2.1 & 1.08 & (a) In the substrate \\
\hline (3) & C-FRCM & 6 & 2.2 & 1.14 & (a) In the substrate \\
\hline (4) & PBO-G-FRCM & 6 & 2.0 & 1.03 & (a) In the substrate \\
\hline
\end{tabular}

\subsection{Pull-off tests}

Pull-off tests are significant to determine the tensile strength of the FRCM composite after the material has been applied to a surface. The tests were performed on specimens of FRCM bonded to the surface of a clay single brick according to EN 1542 [32]. The mechanical characteristics of the bricks are reported in the first part of Chapter 7. The test specimen is formed by drilling a shallow core perpendicular to the surface and leaving the core attached to the brick. This had a depth of $10 \mathrm{~mm}$. A steel disk was attached to the external surface of the core using epoxy adhesive. A tensile loading device was applied to the test specimen coincident with the axis of the specimen. The steel disk had a nominal diameter of 50 $\mathrm{mm}$ and a thickness of $25 \mathrm{~mm}$.

The failure mode can occur:

(a) In the substrate.

(b) At the interface between the substrate and the composite.

(c) At the interface between the mortar and the textile.

(d) In the mortar without involving the textile.

(e) At the interface between the composite and the epoxy adhesive used to fix the steel disk.

Four groups of specimens were tested and the results are reported in Table 13. The G-FRCM specimens showed two different failure modes. Two of them collapsed at the interface between the mortar and the substrate (Fig. 28b). In the others the failure was localized at the interface between mortar and textile (Fig. 28a).
It should be reminded that two different types of bricks were used as reported in Chapter 7.

The obtained results of these pull-off test reflected the different resistance of the bricks. Specimens of series (1), made with GFRCM, were applied on the bricks with a compressive strength of 68.8 MPa and a pull-off resistance of 3.1 MPa. The resulting pulloff load varied between 1.34 and $1.48 \mathrm{MPa}$. The remaining series of specimens were bonded on bricks with lower mechanical properties and showed an ultimate value coincident with the ultimate resistance of the bricks (approximately $1 \mathrm{MPa}$ ).

\section{Conclusions and considerations for future guidelines}

A mechanical characterization of FRCM materials was carried out on different series of specimens. Five types of FRCM materials were studied, composed by different types of PBO, carbon and glass fibers and three types of mortars.

Most of the experiments confirmed that the behavior of FRCM materials in tension can be characterized by trilinear curves. The first part corresponds to the un-cracked phase of the mortar while in the second phase the cracks develop and in the third phase only the fiber reinforcement can carry the applied load. In this phase the measured stiffness and the ultimate strength of the specimens correspond to the relevant values of the dry fabrics.

From the tensile test results on PBO-FRCM, G-FRCM and C-FRCM materials it is possible to conclude that the slopes of the first and second phases are comparable. Instead there are many differences in the third phase, due to the different modulus and 
tensile strengths of the fibers. It is evident that the ultimate strength of PBO is the highest but the envelope of the results is significantly large. On the contrary the small variability of the results for G- FRCM is correlated to the lowest mechanical properties.

The fabric with the highest performance ( $\mathrm{PBO}$ ) provided the best composite behavior in terms of ultimate strength even if the scatter of the results was larger. The specimens made with PBO fibers showed also the best bond properties. The push-pull double lap tests and the pull-off tests showed a good adhesion between the masonry substrate and the FRCM system. Slippage phenomena can occur in samples made with carbon fibers in the third phase of the tensile tests or before the collapse in push-pull shear tests.

The authors believe that the experimental set-up and the results proposed in this paper could be of help to define guidelines for the mechanical characterization of FRCM materials. In particular the following aspect should be considered. The mechanical properties of the composites are influenced by the presence of small defects in the cementitious matrix, by the non-constant dimensions of the section and by the localization of the first cracks with respect to the extensometer. The literature review showed different experimental set-ups used for tensile tests on FRCM materials. The set-up here proposed is the most efficient to avoid damage of the samples and slippage in the grips.

The guidelines shall indicate the method to identify the points of transition between the three phases. If these points are not clearly detected, it is possible to draw the tangent lines and find their intersection. All these parameters must be calculated using the area of the textile. In the un-cracked first phase, the elastic modulus and the maximum stress could be calculated also using the minimum area of the matrix, after a proper detailed geometrical measurement of the thickness and width of the specimens, in order to compare these values with the mechanical properties of the matrix. The analysis of the cracks spacing and size showed a good correlation between the geometry of the fabric and the location of the cracks. This could be an important parameter in the design procedures.

It is suggested that the push-pull and the pull-off tests should be proposed in the guidelines as tools to evaluate the adhesion of the FRCM to the masonry substrate. Among different available test set-ups for push-pull tests, the authors believe that the double lap, as presented in this paper, is the more convenient both in terms of costs and to avoid alignment problems.

A problem that was not considered in this paper refers to the dynamic performance of the FRCM reinforcement [39]. This important issue could be investigated in future steps of this research project.

\section{Acknowledgements}

These tests were performed at the Testing Laboratory for Materials, Structures and Constructions of Politecnico di Milano on specimens produced using reinforcing materials and mortars distributed by Ruredil S.p.A. and Sika Italia S.p.A. Their financial support is gratefully acknowledged. Part of the analyses were developed within the activities of Rete dei Laboratori Universitari di Ingegneria Sismica - ReLUIS for the research program funded by the Dipartimento di Protezione Civile - Progetto Esecutivo 2014.

\section{References}

[1] Triantafillou TC. Composites: a new possibility for the shear strengthening of concrete, masonry and wood. Compos Sci Technol 1998;58:1285-95.

[2] Angelillo M, Babilio E, Cardamone L, Fortunato A, Lippiello M. Some remarks on the retrofitting of masonry structures with composite materials. Compos $B$ 2014;61:11-6.

[3] Triantafillou T, Papanicolaou C. Innovative applications of textile-based composites in strengthening and seismic retrofitting as well as in the prefabrication of new structures. Adv Mater Res 2013;639-640(1):26-41.
[4] Mostofinejad D, Tabatabaei Kashani A. Experimental study on effect of EBR and EBROG methods on debonding of FRP sheets used for shear strengthening of RC beams. Compos B 2013;45:1704-13.

[5] Triantafillou T. Textile-based composite versus FRP as strengthening and seismic retrofitting materials for concrete and masonry structures. In: Concrete repair, rehabilitation and retrofitting III - proceedings of the 3rd international conference on concrete repair, rehabilitation and retrofitting, ICCRRR; 2012. p. 80-8.

[6] Nanni A. FRCM strengthening - a new tool in the concrete and masonry repair toolbox. Concr Int Des Constr 2012;34(4):43-9.

[7] Orlowsky J, Raupach M. Durability model for AR-glass fibers in textile reinforced concrete. Mater Struct 2008;41:1225-33.

[8] Butler M, Mechtecherine V, Hemplel S. Durability of textile reinforced concrete made with AR glass fibre: effect of matrix composition. Mater Struct 2010;43:1351-68.

[9] Pellegrino C, D'Antino T. Experimental behaviour of existing precast prestressed reinforced concrete elements strengthened with cementitious composites. Compos B 2013;55:31-40.

[10] D'Ambrisi A, Focacci F, Caporale A. Strengthening of masonry-unreinforced concrete railway bridges with PBO-FRCM materials. Compos Struct 2013;102: 193-204.

[11] Corradi M, Borri A, Castori G, Sisti R. Shear strengthening of wall panels through jacketing with cement mortar reinforced by GFRP grids. Compos B 2014;64:33-42.

[12] Bruckner A, Ortlepp R, Curbach M. Textile reinforced concrete for strengthening in bending and shear. Mater Struct 2006;39:741-8.

[13] Barhum R, Mechtecherine V. Influence of short dispersed and short integral glass fibres on the mechanical behaviour of textile-reinforced concrete. Mater Struct 2013;46:557-72.

[14] Contamine R, Junes A, Si Larbi A. Tensile and inplane shear behavior of textile reinforced concrete: analysis of a new multiscale reinforcement. Constr Build Mater 2014;51:405-13.

[15] Arboleda D, Loreto G, De Luca A, Nanni A. Material characterization of fiber reinforced cementitious matrix (FRCM) composite laminates. In: Proceedings for 10 th international symposium on ferrocement and thin reinforced cement composite, Havana; 2012.

[16] Zhu D, Peled A, Zaguri E, Mobasher B. Dynamic tensile testing of fabric-cement composites. Constr Build Mater 2011;25:385-95.

[17] Hartig F, Jesse F, Schicktanz K, Haubler-Combe U. Influence of experimental setups on the apparent uniaxial tensile load-bearing capacity of textile reinforced concrete specimens. Mater Struct 2012;45:433-46.

[18] AC 434. Proposed acceptance criteria for masonry and concrete strengthening using fiber-reinforced cementitious matrix (FRCM) composite system; 2011.

[19] Contamine R, Si Larbi A, Hamelin P. Contribution to direct tensile testing of textile reinforced concrete (TRC) composites. Mater Sci Eng A 2011(528): 8589-98.

[20] EN ISO 10618/2005. Carbon fibre - determination of tensile properties of resinimpregnated yarn; 2005.

[21] EN 1015-11. Methods of test for mortar for masonry - determination of flexural and compressive strenght of hardened mortar; 1999.

[22] Mobasher B, Peled A, Pahilajani J. Distributed cracking and stiffness degradation in fabric-cement composites. Mater Struct 2006;39:317-31.

[23] D’Antino T, Sneed LH, Carloni C, Pellegrino C. Matrix-fiber bond behavior in PBO FRCM composites: a fracture mechanics approach. Eng Fract Mech 2014:117:94-111.

[24] Valluzzi MR et al. Round robin test for composite-to-brick shear bond characterization. Mater Struct 2012;45(12):1761-91.

[25] D'Ambrisi A, Feo L, Focacci F. Experimental analysis on bond between PBO-FRCM strengthening materials and concrete. Compos B 2012;44(1): 524-32.

[26] Ceroni F, Ferracuti B, Pecce M, Savoia M. Assessment of a bond strength model for FRP reinforcement externally bonded over masonry blocks. Compos B 2014;61:147-61

[27] Carozzi FG, Milani G, Poggi C. Mechanical properties and numerical modeling of Fabric Reinforced Cementitious Matrix (FRCM) systems for strengthening of masonry structures. Compos Struct 2014;107:711-25.

[28] Peled A, Zaguri E, Marom G. Bonding characteristics of multifilament polymer yarns and cement matrices. Compos A 2008;39:930-9.

[29] Soranakom C, Mobasher B. Geometrical and mechanical aspects of fabric bonding and pullout in cement composites. Mater Struct 2009;42:765-77.

[30] Andic-Cakir O, Sarijanat M, Tufekci HB, Demirci C, Erdogan UH. Physical and mechanical properties of randomly oriented coir fiber-cementitious composites. Compos B 2014;61:49-54.

[31] Banholzer B, Brockmann T, Brameshuber W. Material and bonding characteristics for dimensioning and modelling of textile reinforced concrete (TRC) elements. Mater Struct 2006;39:749-63.

[32] EN 1542. Products and systems for the protection and repair of concrete structures - test methods - measurement of bond strength by pull-off; 2000 .

[33] EN 12390-6. Testing hardened concrete. Tensile splitting strength of test specimens; 2009.

[34] EN 14580. Natural stone test methods. Determination of the static elastic modulus; 2005.

[35] ACI 549.4R-13. Guide to design and construction of externally bonded cementitious matrix (FRCM) systems for repair and strengthening concrete and masonry structures. American Concrete Institute, Report by ACI Committee 549. 
[36] De Felice G et al. Mortar-based system for externally bonded strengthening of masonry. Mater Struct 2014;47:2021-37.

[37] Malena M, De Felice G. Debonding of composites on a curved masonry substrate: Experimental results and analytical formulation. Compos Struct 2014;112:194-206.
[38] Bertolesi E, Carozzi FG, Milani G, Poggi C. Numerical modelling of Fabric Reinforced Cementitious Matrix composites (FRCM) in tension. Constr Build Mater 2014;70:531-48.

[39] Angelillo M, Cardamone L, Fortunato A. A numerical model for masonry-like structures. J Mech Mater Struct 2010;5:583-615. 